\title{
Article \\ Robust Detection of Somatic Mosaicism and Repeat Interruptions by Long-Read Targeted Sequencing in Myotonic Dystrophy Type 1
}

\author{
Antoine Mangin ${ }^{1,2}$, Laure de Pontual ${ }^{1}$, Yu-Chih Tsai ${ }^{3}\left[{ }^{1}\right.$, Laetitia Monteil ${ }^{4}$, Mathilde Nizon ${ }^{5}$, Pierre Boisseau ${ }^{5}$, \\ Sandra Mercier ${ }^{6}{ }^{(}$, Janet Ziegle ${ }^{3}$, John Harting ${ }^{3}$, Cheryl Heiner ${ }^{3}$, Geneviève Gourdon ${ }^{1}$ and Stéphanie Tomé ${ }^{1, *}$ \\ 1 Centre de Recherche en Myologie, Inserm, Institut de Myologie, Sorbonne Université, F-75013 Paris, France; \\ mangina@cardiff.ac.uk (A.M.); l.depontual@institut-myologie.org (L.d.P.); \\ genevieve.gourdon@inserm.fr (G.G.) \\ 2 Dementia Research Institute, Cardiff University, Cardiff CF10 3AT, UK \\ 3 Pacific Biosciences, Menlo Park, CA 94025, USA; ytsai@pacificbiosciences.com (Y.-C.T.); \\ jziegle@pacificbiosciences.com (J.Z.); jharting@pacificbiosciences.com (J.H.); \\ cheiner@pacificbiosciences.com (C.H.) \\ 4 Genetics Department of the Hospital of Toulouse, F-31059 Toulouse, France; monteil.1@chu-toulouse.fr \\ 5 CHU de Nantes, Service de Génétique Médicale, Laboratoire de Génétique Moléculaire, F-44000 Nantes, \\ France; mathilde.nizon@chu-nantes.fr (M.N.); pierre.boisseau@chu-nantes.fr (P.B.) \\ 6 CHU Nantes, Service de Génétique Médicale, Centre de Référence des Maladies Neuromusculaires AOC, \\ F-44000 Nantes, France; Sandra.MERCIER@chu-nantes.fr \\ check for \\ * Correspondence: stephanie.tome@inserm.fr; Tel.: +33-1-42-16-57-16; Fax: +33-1-42-16-57-00
} updates

Citation: Mangin, A.; de Pontual, L.; Tsai, Y.-C.; Monteil, L.; Nizon, M.; Boisseau, P.; Mercier, S.; Ziegle, J.; Harting, J.; Heiner, C.; et al. Robust Detection of Somatic Mosaicism and Repeat Interruptions by Long-Read Targeted Sequencing in Myotonic Dystrophy Type 1. Int. J. Mol. Sci. 2021, 22, 2616. https://doi.org/ $10.3390 /$ ijms22052616

Academic Editor: Irmgard Tegeder

Received: 12 February 2021

Accepted: 27 February 2021

Published: 5 March 2021

Publisher's Note: MDPI stays neutral with regard to jurisdictional claims in published maps and institutional affiliations.

Copyright: (c) 2021 by the authors. Licensee MDPI, Basel, Switzerland. This article is an open access article distributed under the terms and conditions of the Creative Commons Attribution (CC BY) license (https:// creativecommons.org/licenses/by/ $4.0 /)$.

\begin{abstract}
Myotonic dystrophy type 1 (DM1) is the most complex and variable trinucleotide repeat disorder caused by an unstable CTG repeat expansion, reaching up to 4000 CTG in the most severe cases. The genetic and clinical variability of DM1 depend on the sex and age of the transmitting parent, but also on the CTG repeat number, presence of repeat interruptions and/or on the degree of somatic instability. Currently, it is difficult to simultaneously and accurately determine these contributing factors in DM1 patients due to the limitations of gold standard methods used in molecular diagnostics and research laboratories. Our study showed the efficiency of the latest PacBio long-read sequencing technology to sequence large CTG trinucleotides, detect multiple and single repeat interruptions and estimate the levels of somatic mosaicism in DM1 patients carrying complex CTG repeat expansions inaccessible to most methods. Using this innovative approach, we revealed the existence of de novo CCG interruptions associated with CTG stabilization/contraction across generations in a new DM1 family. We also demonstrated that our method is suitable to sequence the DM1 locus and measure somatic mosaicism in DM1 families carrying more than 1000 pure CTG repeats. Better characterization of expanded alleles in DM1 patients can significantly improve prognosis and genetic counseling, not only in DM1 but also for other tandem DNA repeat disorders.
\end{abstract}

Keywords: myotonic dystrophy type 1; long read sequencing; somatic mosaicism; interrupted CTG repeat expansion

\section{Introduction}

More than 40 different human disorders are caused by tri-, tetra-, penta- or hexanucleotide repeat expansions localized either in coding or non-coding regions of the target gene [1]. The pathogenic mechanisms for repeat diseases involve either a loss of protein function or a gain of function at the RNA or protein level, depending on the type and location of the repeat [1]. Among the trinucleotide repeat (TNR) diseases, Fragile X syndrome (FXS (MIM: 300624)), Huntington's disease (HD (MIM: 143100)), several spinocerebellar ataxias (SCAs) and myotonic dystrophy type 1 (DM1 (MIM: 160900)) have been reported. DM1 is a highly multisystemic disorder caused by an unstable CTG repeat expansion 
within the $3^{\prime}$-untranslated region (UTR) of the myotonic dystrophy protein kinase (DMPK) gene that usually increases across generations and in tissues [2,3]. DM1 is mainly characterized by a broad clinical spectrum of symptoms such as myotonia, muscle weakness, cardiac conduction defect, respiratory insufficiency, dysphagia, gastrointestinal symptoms, somnolence or cataracts [4]. Several parameters such as the CTG repeat length and gender contribute to the phenotypic variability of DM1, resulting in five distinct clinical forms from late onset to the most congenital cases, which are often associated with the largest size of inherited disease-associated allele [4,5]. Facial dysmorphisms, muscle weakness and cognitive impairment are more frequent symptoms in earlier onset form while cardiac defects and cataracts are seen more in DM1 patients with later forms of the disease. Interestingly, gastrointestinal problems or dysphagia and insomnia are found in all five forms of DM1 described in a large French DM1 cohort [4]. However, many DM1 patients develop unusual DM1 symptoms or remain asymptomatic despite the presence of a large CTG repeat expansion in their cells. This suggests that contributing factors such as somatic mosaicism, gene modifiers and environmental factors may affect the evolution of the clinical and mutation aspects $[3,6,7]$. The somatic mosaicism observed in blood is strongly biased towards expansions and contributes not only to the progressive nature of the different symptoms in several DM1 ethnic groups, but also to the variation in the age of onset [6,8-10]. Two studies also revealed that single-nucleotide polymorphisms in the MutS Homolog 3 (MSH3) DNA mismatch repair gene may reduce somatic mosaicism levels but also delay onset in DM1 patients [11,12].

More recently, interrupted TNR alleles have been associated with stabilization of TNR repeat loci and a change in clinical features in DM1 as well as in other TNR diseases such as fragile X-associated tremor/ataxia syndrome (FXTAS (MIM: 300623)) or fragile X-associated primary ovarian insufficiency and SCA1 (MIM: 164400) [13-23]. Several studies have described various types of interruptions in the $5^{\prime}$ and $3^{\prime}$ ends of the CTG expanded allele in $3-8 \%$ of the DM1 population [16-32]. These interruptions are associated with stabilization of CTG repeat expansion and atypical clinical features. Most CCG interruptions are often associated with milder DM1 symptoms and/or additional symptoms [17-19,21,23]. Interrupted CTG repeat sequences have been associated with late onset of symptoms and severe atypical axial and proximal weakness. No milder symptoms have been described in Spanish DM1 patients with interrupted CTG repeat expansion [21]. Compared to the TNR-coding diseases and FXS, the type, number and position of interruptions are extremely variable in DM1. The disparity of interruptions may explain the broad clinical spectrum observed in patients carrying interrupted sequences and may also make it difficult to understand the role of these interruptions on the phenotype.

Accurate estimation of the size of inherited CTG repeat expansion, somatic mosaicism and identification of interrupted alleles are crucial to better characterize the genotypephenotype correlation in DM1. Inherited CTG repeat expansion size and the level of somatic mosaicism are traditionally evaluated by Southern blot, polymerase chain reaction (PCR) and small pool PCR [33]. These methods do not provide any information on the sequence of CTG repeat expansion. Only triplet-primed PCR may detect the presence of interruptions at the $5^{\prime}$ and $3^{\prime}$ ends of the CTG repeat expansion [34]. Identification of interruptions may be resolved by short-read sequencing or by enzymatic digestion [17,34]. However, the information obtained is limited to the end of the sequence and gives no information about the middle of the sequence.

Long-read sequencing has recently been successfully applied in HD and Fragile $X$ patients and also in DM1 patients [18,35-38]. The Monckton group analyzed the CTG repeat expansions in different DM1 patients with less than 400 CTG repeats using a new long-read technology, single molecule real-time (SMRT) sequencing by Pacific Biosciences (PacBio), and the penultimate PacBio RSII System [18]. They showed that CCG interruptions are exclusively localized at the ends of the sequence and are associated with milder symptoms in DM1 patients with $<400$ CTG repeat tracts. Today, no method has been described to study 
both the size of large CTG repeats, the presence of interruptions and somatic mosaicism in DM1.

The present study is an extension of previously reported results in DM1 patients using the latest generation of long-read sequencing developed by PacBio and amplicons as resources. We have shown that the new PacBio technology can sequence at least 1000 CTG repeats, detect a single CAG and multiple CCG interruptions and estimate somatic mosaicism at the same time with sufficient depth. In this study, we described a paternal de novo CCG interruption in a new DM1 family. We also characterized the CTG repeat sequence and its haplotype in seven individuals of a large family (three generations) carrying a DM1 intermediate allele (37 repeats). We have identified the stable interrupted hexamer allele (CCGCTG) associated with the European DM1 haplotype A. More complete characterization of the expanded allele in DM1 patients will improve our knowledge on the genotype-phenotype correlation in DM1 as well as the prognosis and genetic counseling in this disease and other TNR disorders.

\section{Results}

\subsection{De Novo CCG Interruption in New DM1 Family Identified with the Sequel II System}

Family E was recruited for prenatal genetic counseling. E2.1 was identified as a DM1 patient carrying interrupted CTG repeat expansion with atypical symptoms. In order to improve the genetic counseling in this family, we mainly characterized the DMPK mutation in DM1 members of this family. PCR amplification of the CTG repeat tracts revealed a decrease in CTG repeat size across two paternal transmissions (Figure 1). Bidirectional triplet-primed polymerase chain reaction (TP-PCR) showed several interruptions at the $3^{\prime}$ end of the CTG repeat in individuals E2.1 and E3. However, the TP-PCR trace is different between E2.1 and E.3 (Figure 2). Two distinct gaps were found in both TP-PCR traces, whereas a third gap was only observed in individual E.3, introducing the presence of additional interruptions in the fetus E3. Interestingly, the $3^{\prime}$ end of the repeat appeared free of interruption in individual E.1 (Figure 2). By cloning and sequencing the CTG repeat tracts, we identified a majority of expanded $D M P K$ alleles with two and six non-consecutive CCG interruptions in the $3^{\prime}$ of the CTG expansion of E2.1 and E3, respectively, whereas no interruption was identified in individual E1 in the ends of the CTG repeat expansion (Figure 3). These first results suggest de novo mutation in this family. However, the TP-PCR method and cloning sequencing did not allow the characterization of the middle of the expanded repeats in this family, particularly in individual E1 with the largest expanded allele. In order to definitively exclude the presence of interruption in the unsequenced CTG repeat region by conventional methods in E1, we analyzed around 10,000 molecules of $D M P K$ alleles from the blood of family E using SMRT sequencing on the Sequel II System. First, we sequenced the full repeat expansion for each patient and accurately estimated the size of the CTG expansion. The mode of the CTG repeat size frequency distribution was 447, 383 and 173/215 CTG repeats in E1, E2.1 and E3 individuals, respectively (Table 1). In the E3 fetus, the CTG repeat length distribution was bimodal with a mode at $\sim 173$ and 215 compared to the individuals E1 and E2 which show a unimodal distribution. We identified CCG interrupted alleles exclusively in individuals E2.1 and E3 whereas the individual E1 carried a pure expanded allele (Figure 4 and Table 1). Interestingly, the SMRT sequencing revealed cells carrying a majority of expanded DMPK alleles with two or three CCG interruptions in individual E2.1, suggesting that the number of interruptions varies between cells in blood (Table 1 and data not shown). The results of SMRT sequencing confirm that de novo interruptions occur during the E1 and E2.1 paternal transmission. 
a)

\section{E1}

$(5,447)$

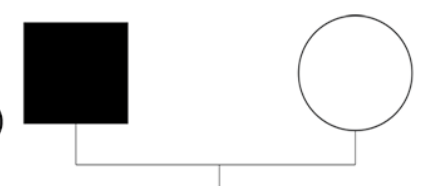

E2.1

$(13,383)$

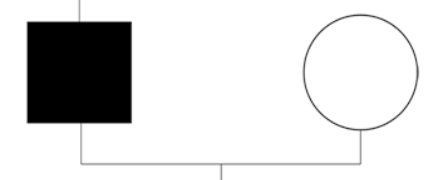

\section{E2.2}

\section{E3}

(31, 173-215)

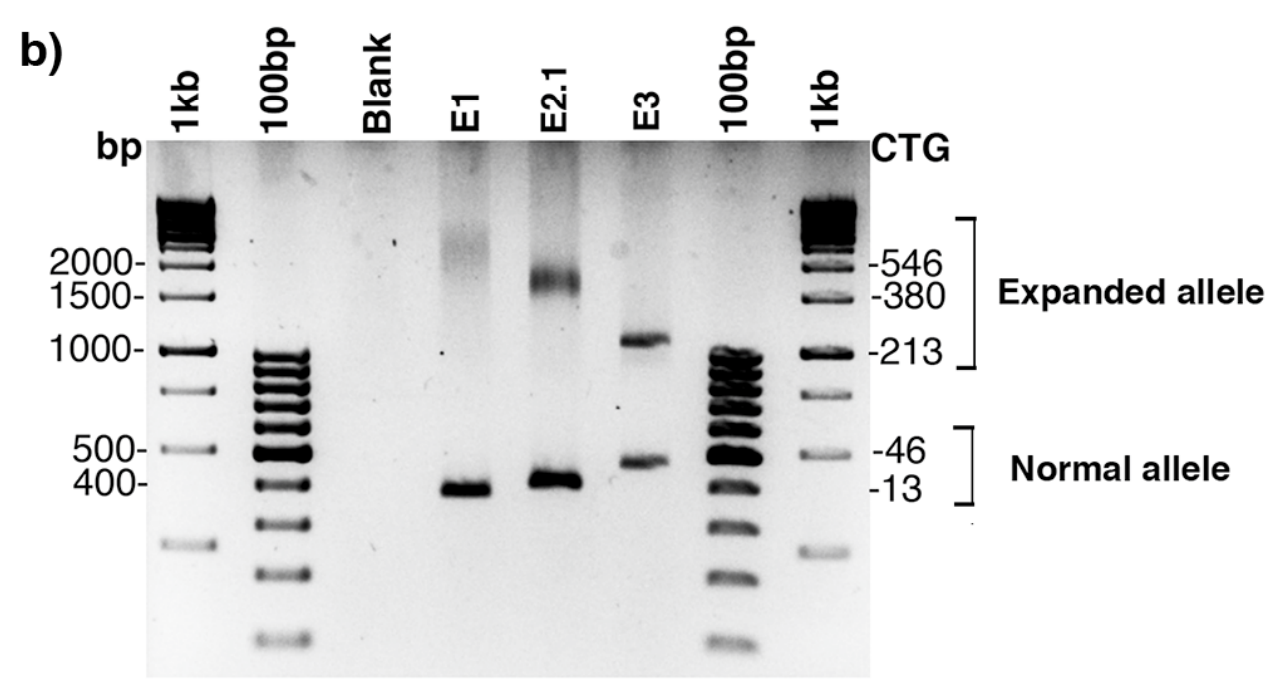

Figure 1. Atypical myotonic dystrophy type 1 (DM1) family E. (a) Part of family E pedigree. CTG repeat length estimated by Sequel II System is placed in parentheses. (b) PCR amplification of the CTG repeats. Normal and expanded alleles are indicated in brackets. The sizes of DNA molecular weight $1 \mathrm{~kb}$ (Thermo Fisher Scientific, Courtaboeuf, France) in base pairs and in the number of CTG repeats are shown on the left and the right sides of the figure, respectively.

2.2. Sequel II System Makes It Possible to Estimate the CTG Repeat Length and the Interruptions as Well as the Somatic Mosaicism in DM1 Patients with at Least 1000 CTG Repeats

Using data generated by the Sequel II System, we were able to sequence CTG repeat expanded allele in individuals E1, E2.1 and E3 and then accurately estimate the size of the repeat and the number of interruptions. Interestingly, SMRT sequencing also allowed for quantifying the degree of somatic mosaicism in these DM1 patients. The level of somatic mosaicism is higher in individuals E1 than E3 (Figure 5). To support the efficiency of SMRT sequencing in DM1 and to strengthen our data, we also analyzed the CTG repeat expansions in patients A4.1 (single CAG interruption) and B2 (3 CCG interruption) and two DM1 patients (1201 and 5289) with pure CTG repeat expansions published in Tomé et al. (Table 1 and [16]). As previously described, we identified a single CAG repeat interruption in individual A4.1 and three CCG interruptions in individual B2 (Figure 6a and Table 1). In addition, somatic mosaicism was observed in four DM1 patients, with lower somatic mosaicism in individuals A4.1 and B2 compared to the respective DM1 patients with pure repeats as reported in Tomé et al. (Figure 6b). For the first time, we also succeeded in sequencing the DM1 locus and estimated somatic mosaicism in the DM1 family (patients L2 and L3) carrying more than 1000 pure CTG repeats using the Sequel II System (Figure 7 and Table 1). The mode of the CTG repeat size frequency distribution was 957 and 1156 
repeats in individuals L2 and L3, respectively (Table 1). No interruption was identified (Figure 7a) and a high somatic mosaicism was observed in these two patients where the largest expanded allele contained 2138 CTG repeats (Figure $7 \mathrm{~b}$ ). We have shown that the Sequel II System successfully analyzes the sequence of CTG repeats in DM1 patients carrying more than 1000 CTG repeats, the degree of somatic mosaicism and the variant in a single analysis.

\section{3'TP-PCR}

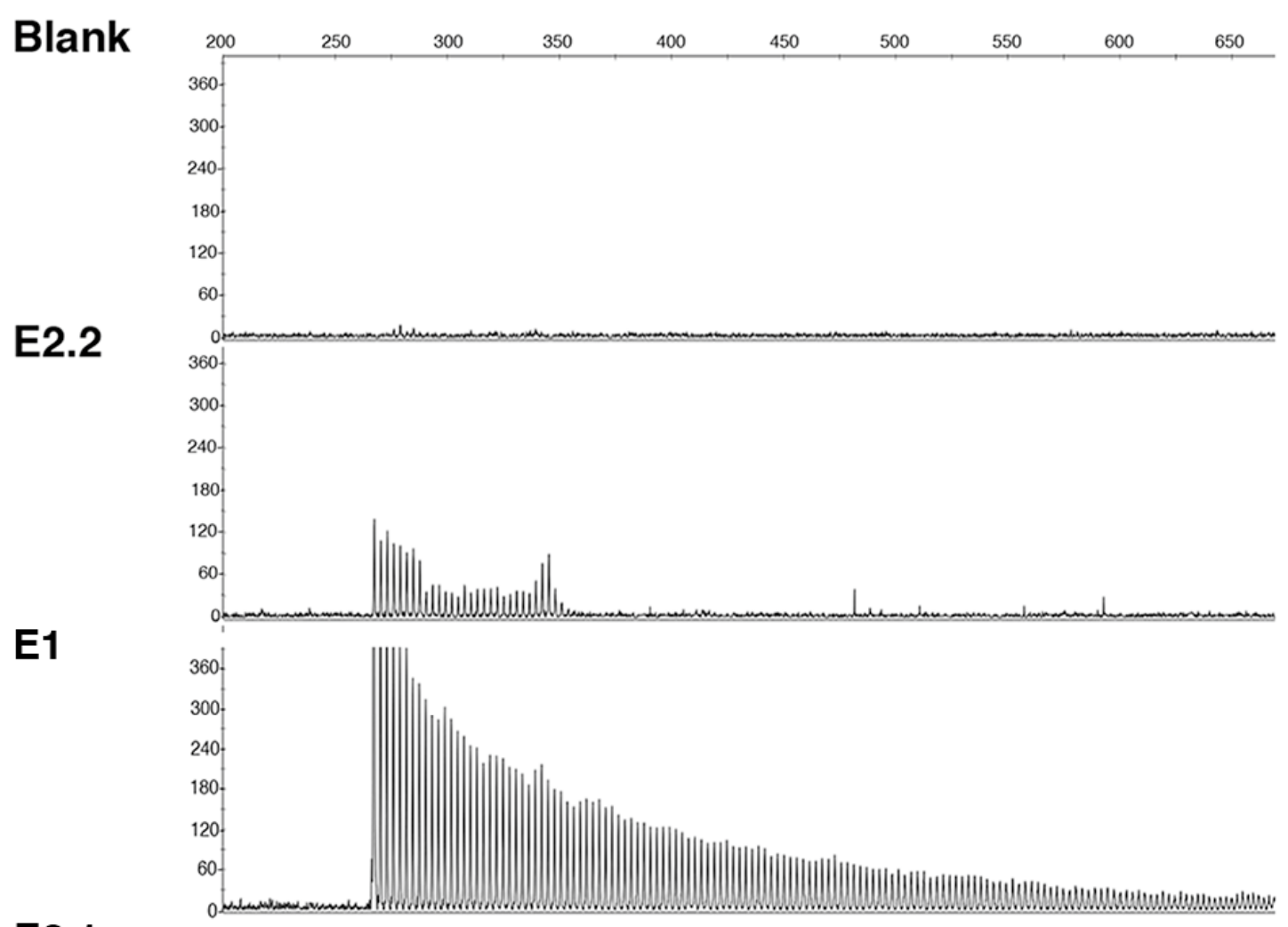

E2.1

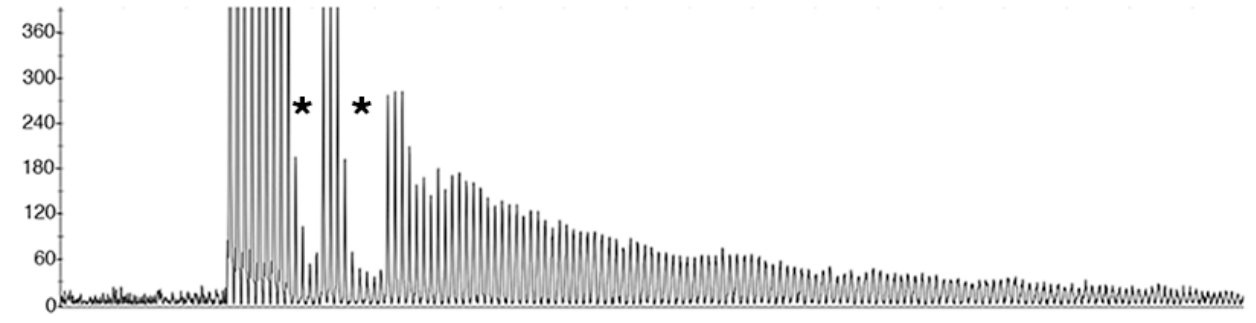

E3

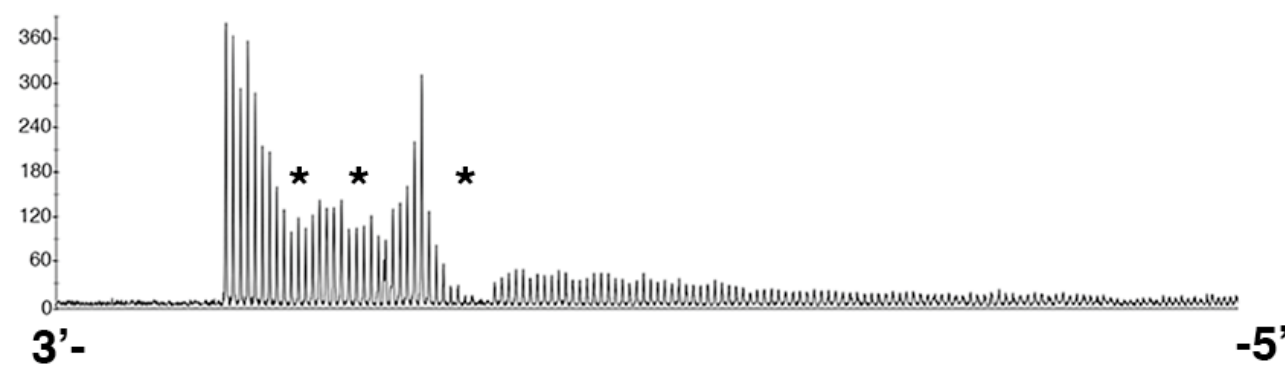

Figure 2. $3^{\prime}$ triplet-primed polymerase chain reaction (TP-PCR) results in individuals from family E. The $y$-axis represents the intensity of fluorescence (arbitrary unit) and the $x$-axis represents the fragment length in base pair. An asterisk (*) indicates the localization of the interruptions. 
E1

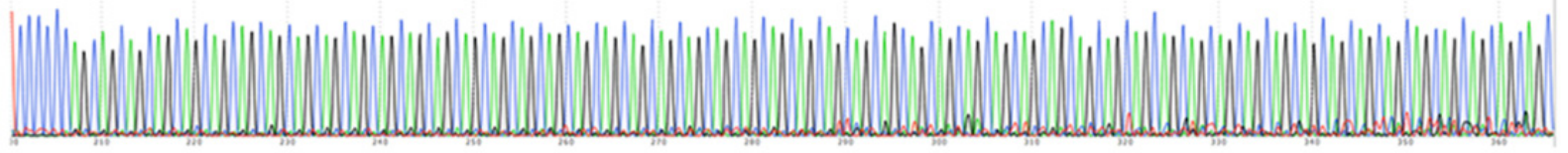

E2.1

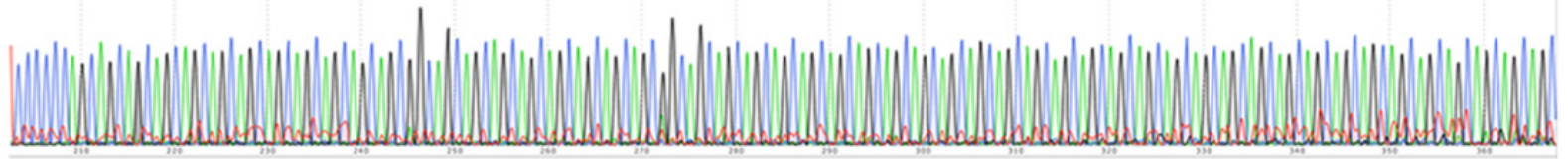

E3

3'-

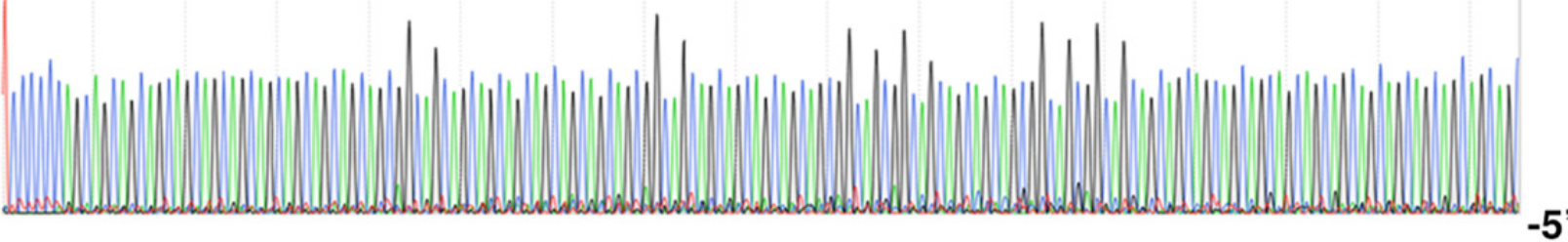

Figure 3. DM1 locus sequences in the family E (cloning sequencing). GGC (CCG) interruptions are underlined.

Table 1. Sequel II results in family E and L2 and L3 patients carrying more than 1000 CTG repeats.

\begin{tabular}{|c|c|c|c|c|c|c|c|c|c|c|}
\hline Sample & $\begin{array}{l}\text { Total } \\
\text { CCS } \\
\text { Reads }\end{array}$ & $\begin{array}{c}\text { \% CCS } \\
\text { Reads } \\
\text { on-Target }\end{array}$ & $\begin{array}{c}\% \\
\text { on-Target } \\
\text { Reads Full- } \\
\text { Length }\end{array}$ & $\begin{array}{c}\text { Full } \\
\text { DM1 } \\
\text { Reads }\end{array}$ & $\begin{array}{c}\text { Total } \\
\text { Reads } \\
\text { Analyzed }\end{array}$ & $\begin{array}{l}\text { Reads < } \\
50 \text { CTG }\end{array}$ & $\begin{array}{c}\text { Reads } \geq \\
50 \text { CTG }\end{array}$ & $\begin{array}{l}\% \text { Ex- } \\
\text { panded } \\
\text { Allele }\end{array}$ & $\begin{array}{l}\text { Estimated } \\
\text { Repeat Size } \\
\text { (Mode) }\end{array}$ & $\begin{array}{c}\text { CCG } \\
\text { Interruptions }\end{array}$ \\
\hline E1 & 94,411 & 99.37 & 84 & 79,224 & 10,000 & 724 & 9276 & 93 & $\begin{array}{c}5, \sim 447 \\
(1099 \text { max rpt) }\end{array}$ & $\begin{array}{l}\text { No obvious } \\
\text { interruption }\end{array}$ \\
\hline E2.1 & 110,578 & 99.54 & 87 & 95,756 & 9999 & 627 & 9372 & 94 & $\begin{array}{c}13, \sim 383 \\
(831 \text { max rpt) }\end{array}$ & $2-3 \times C C G$ \\
\hline E3 & 67,182 & 99.61 & 89 & 59,342 & 10,000 & 375 & 9625 & 96 & $\begin{array}{c}\text { 31, } \sim 173 \text { and } \\
\sim 215 \\
\text { (478 max rpt) }\end{array}$ & $6 \times C C G$ \\
\hline L2 & 48,310 & 99.10 & 79 & 37,727 & 10,000 & 1291 & 8709 & 87 & $\begin{array}{c}5, \sim 957 \\
(2138 \text { max rpt) }\end{array}$ & $\begin{array}{l}\text { No obvious } \\
\text { interruption }\end{array}$ \\
\hline L3 & 29,512 & 99.02 & 77 & 22,625 & 9999 & 1670 & 8329 & 83 & $\begin{array}{c}5, \sim 1156 \\
(2081 \text { max rpt) }\end{array}$ & $\begin{array}{l}\text { No obvious } \\
\text { interruption }\end{array}$ \\
\hline A 4.1 & 50,300 & 99.62 & 89 & 44,745 & 10,000 & 721 & 9279 & 93 & $\begin{array}{c}5, \sim 109 \\
(245 \text { max rpt) }\end{array}$ & $1 \times C A G$ \\
\hline 1201 & 37,407 & 99.44 & 85 & 31,683 & 9999 & 1813 & 8186 & 82 & $\begin{array}{c}5, \sim 118 \\
(619 \text { max rpt) }\end{array}$ & $\begin{array}{l}\text { No obvious } \\
\text { interruption }\end{array}$ \\
\hline B2 & 57,255 & 99.3 & 84 & 47,745 & 9995 & 1075 & 8920 & 89 & $\begin{array}{c}\text { 5, } \sim 292 \\
(802 \text { max rpt) }\end{array}$ & $3 \times C C G$ \\
\hline 5289 & 42,349 & 99.31 & 82 & 34,690 & 9994 & 1595 & 8399 & 84 & $\begin{array}{c}5, \sim 185 \\
(896 \text { max rpt) }\end{array}$ & $\begin{array}{l}\text { No obvious } \\
\text { interruption }\end{array}$ \\
\hline
\end{tabular}




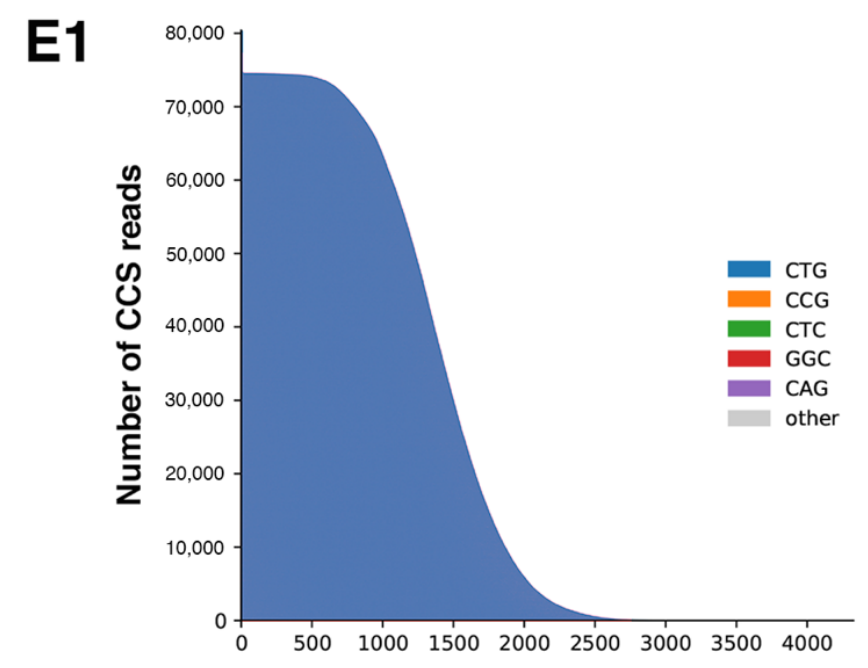

E2.1
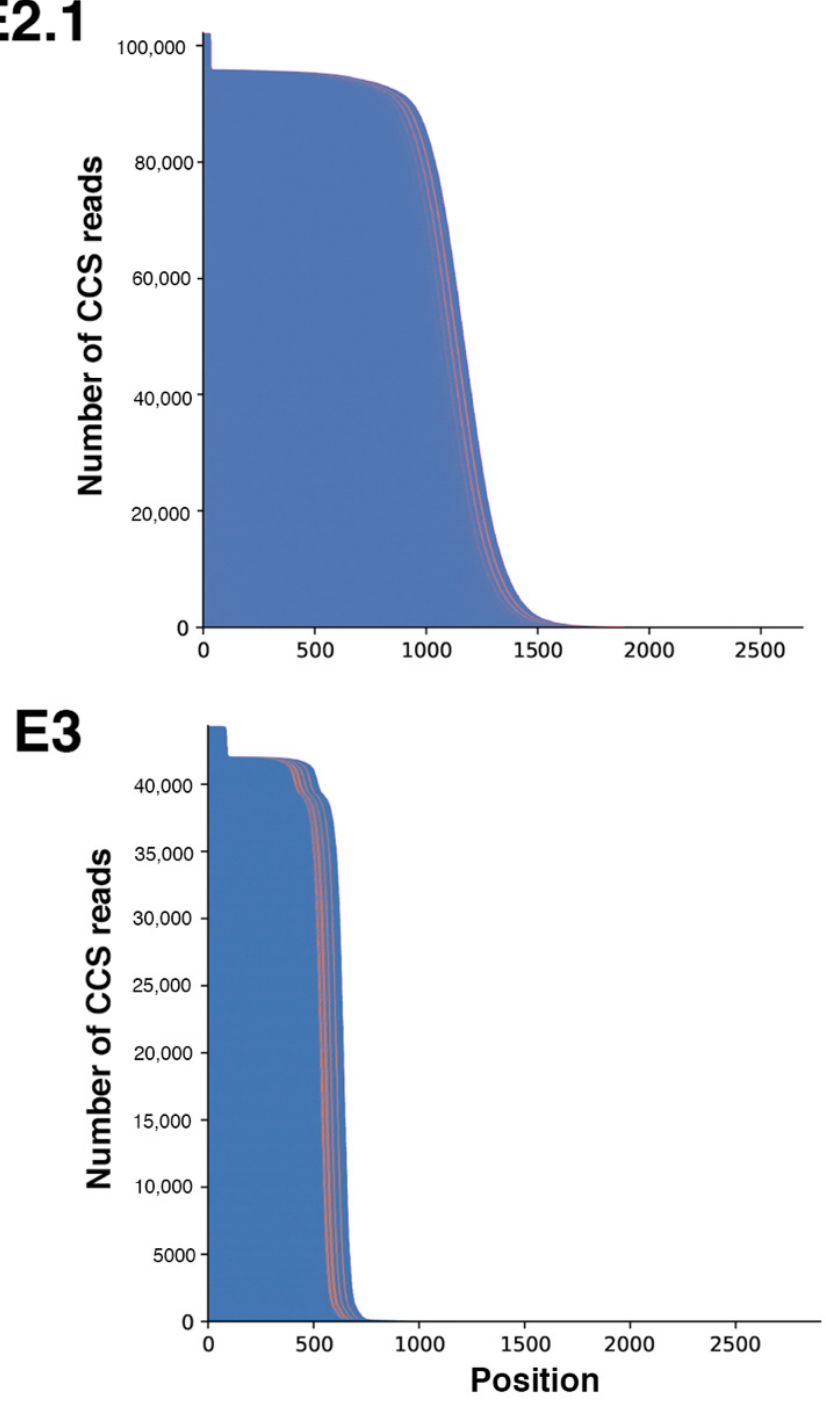

Figure 4. Waterfall plots outline the repeat structure of the normal and expanded alleles in family E. The $y$-axis shows the number of circular consensus sequencing (CCS) reads whereas the $x$-axis shows the length of the CTG repeat expansion in base pairs. The CTG repeat is represented in blue whereas the CCG interruptions are represented in orange. The highest peaks at the far left of the distribution represent the normal allele. 


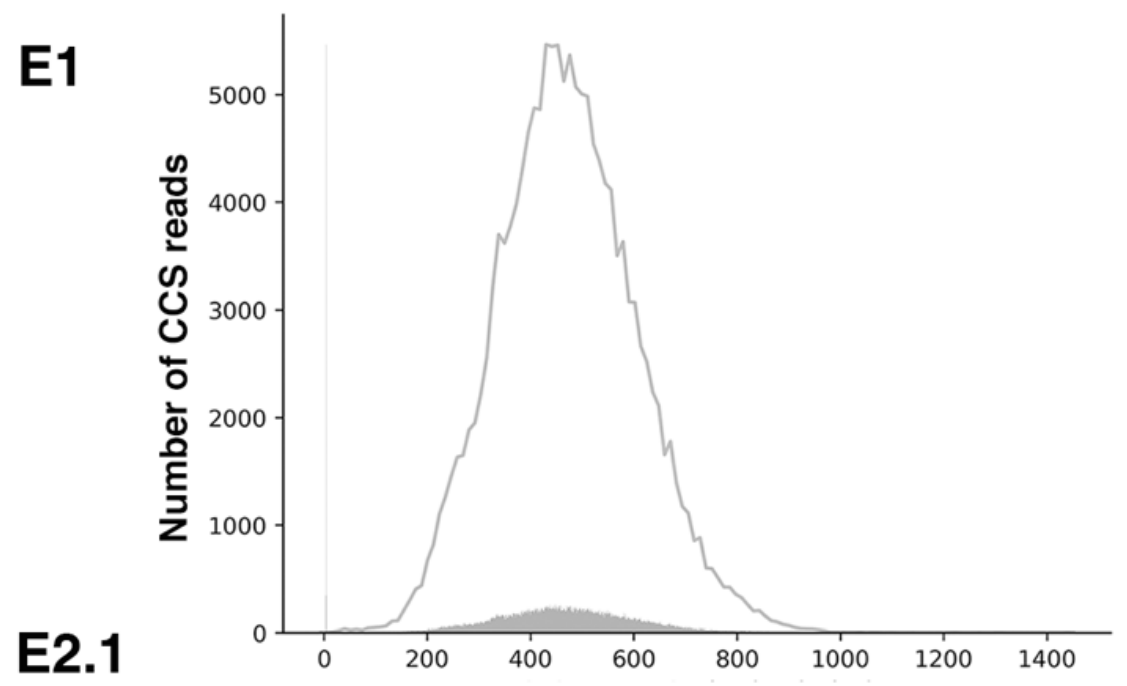

E3
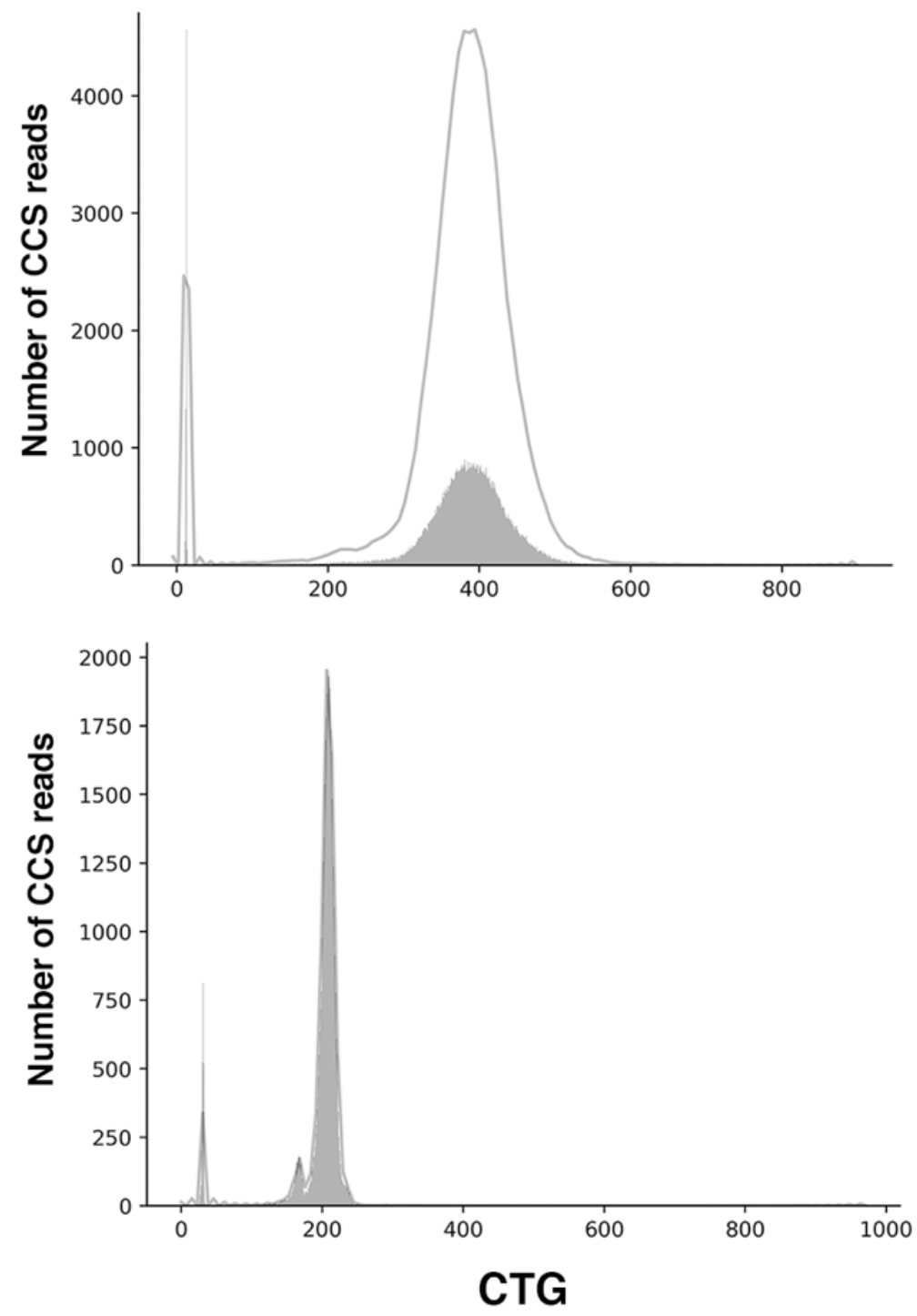

Figure 5. CTG repeat size distribution in family E. The $y$-axis shows the number of CSS reads in the solid grey distribution, whereas the $x$-axis shows the number of CTG repeats. Repeat counting allows to confirm allele sizes for both normal and expanded alleles as well as the extent of mosaicism of the expanded allele. The grey line represents a kernel density estimation of the underlying solid grey distribution of CCS reads. 
a

A4.1

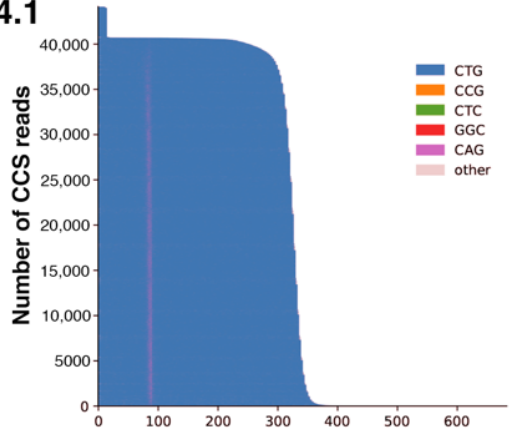

1201

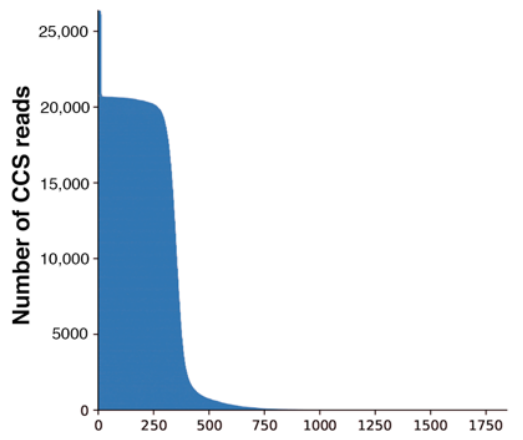

B2

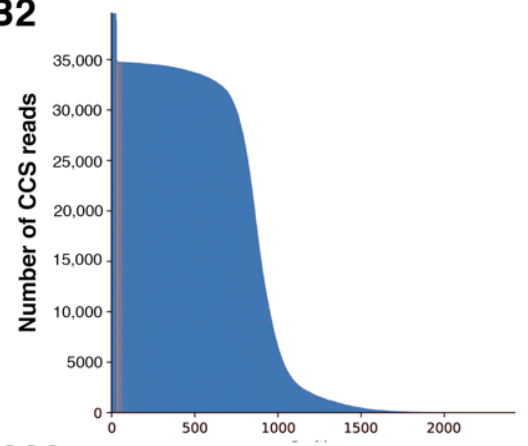

5289

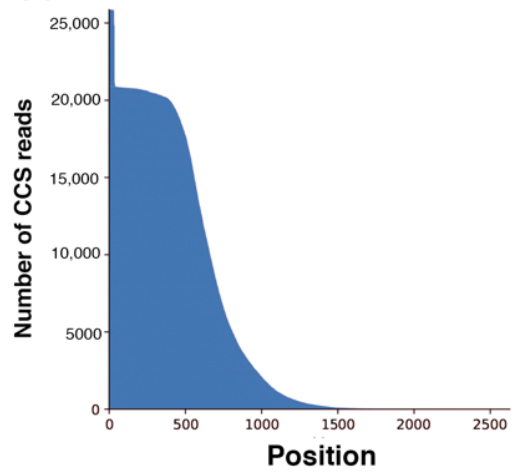

b
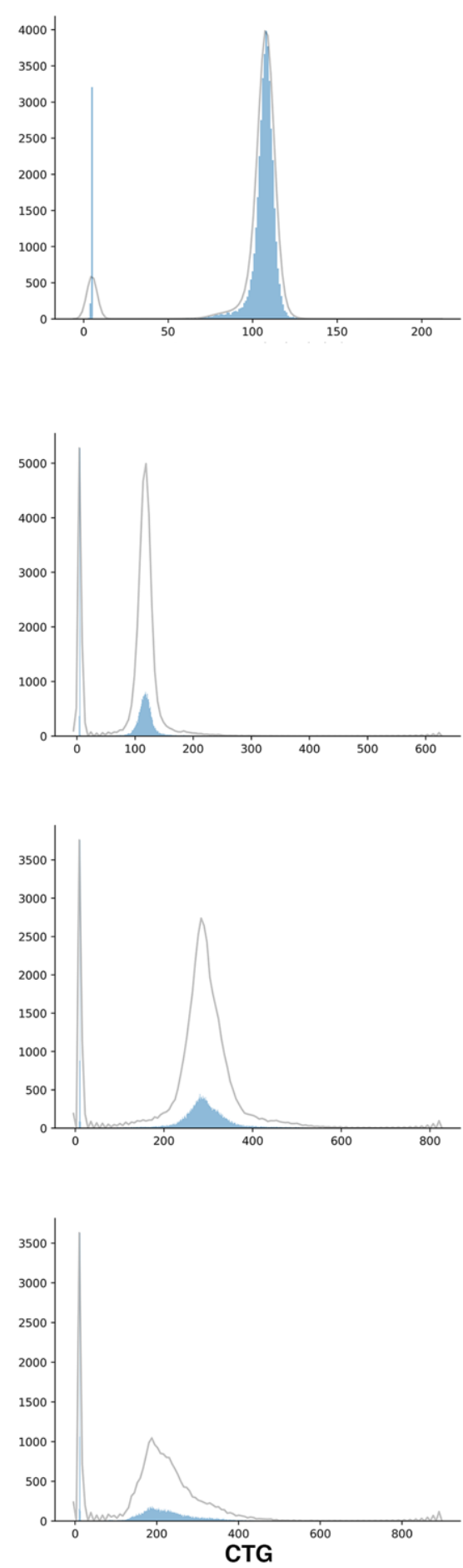

Figure 6. Long-read sequencing results in four DM1 patients (a)-Waterfall plots outline the repeat structure of the normal and expanded alleles. The $y$-axis shows the number of CSS reads whereas the $x$-axis shows the length of the CTG repeat expansion in base pairs. The CTG repeat is represented in blue whereas the CAG interruption is represented in purple and the CCG interruptions are represented in orange. The highest peaks represent the normal allele. (b) - CTG repeat size distribution. The $y$-axis shows the number of CSS reads in the solid blue distribution, whereas the $x$-axis shows the number of CTG repeats. The grey line represents a kernel density estimation of the underlying blue distribution of CCS reads. A4.1 (CAG interrupted expansion), B2 (CCG interrupted expansion), 1201 and 5289 carry pure CTG repeat expansions. 

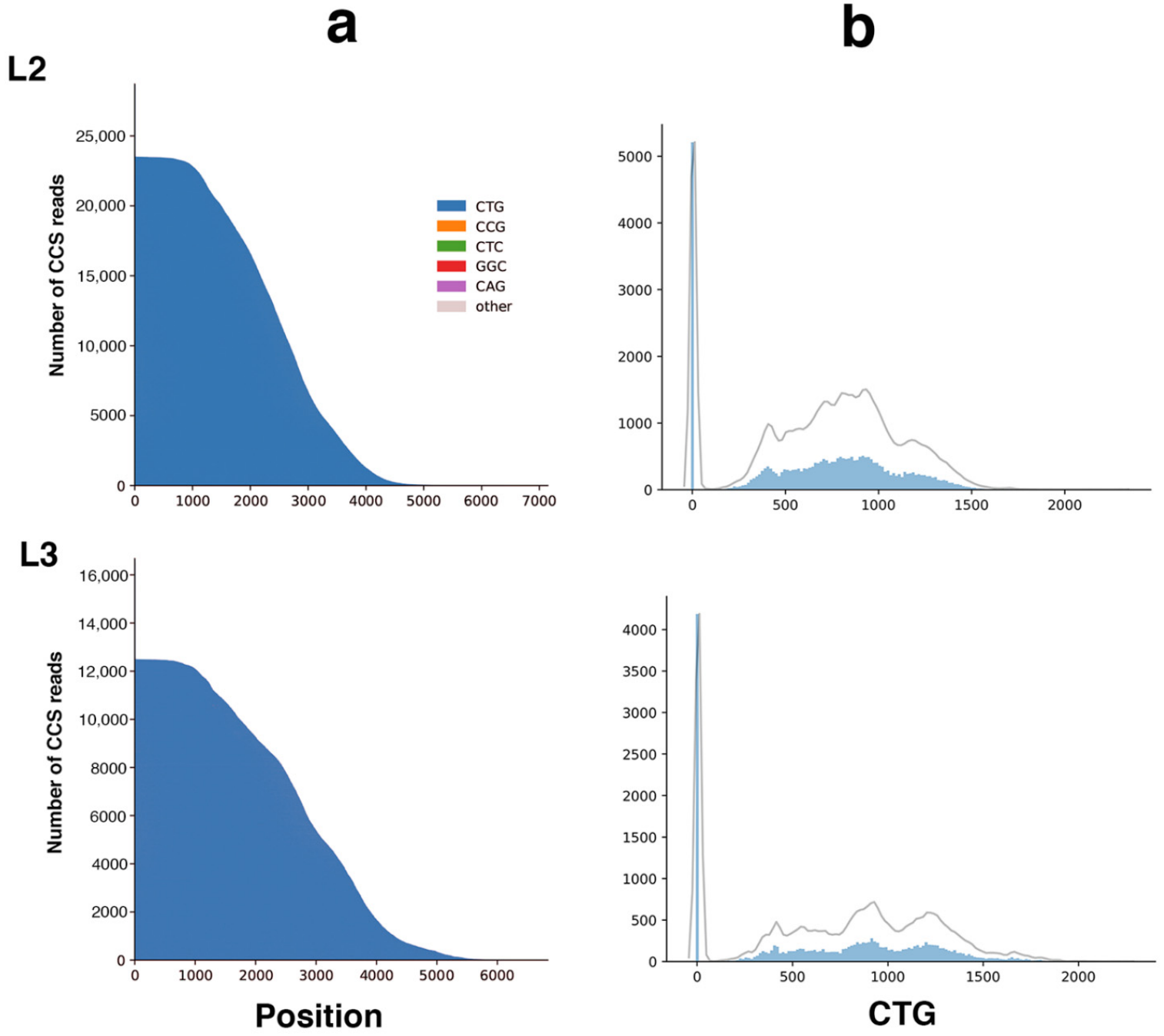

Figure 7. Long-read sequencing results in individuals L2 and L3 carrying more than 1000 CTG repeats. (a)—Waterfall plots outline the repeat structure of the normal and expanded alleles. The $y$-axis shows the number of CSS reads, whereas the $x$-axis shows the length of the CTG repeat expansion in base pairs. The CTG repeat is represented in blue. The highest peaks at the far left of the distribution represent the normal allele. (b) - CTG repeat size distribution in DM1 patients with more than 1000 CTG repeats estimated at diagnosis. The $y$-axis shows the number of CSS reads in the solid blue distribution, whereas the $x$-axis shows the length of the CTG repeat expansion. The grey line represents a kernel density estimation of the underlying blue distribution of CCS reads.

\subsection{Stable CCG-Interrupted Allele with 37 Repeats Is Associated to DM1 Haplotype in a Large Family}

DM1 disease was suspected during maternal and fetal monitoring in the individual G3.2 from the G37 family (Figure 8a). By classic PCR and Sanger sequencing, we identified a 37-CTG repeat allele in the individuals G3.1 and G3.2 as well as in the other members of the family, excluding the presence of DM1 in this family (Figure 8). This allele is stably transmitted across successive generations as expected. In order to better characterize the nature of the CTG repeat locus in this family, we utilized TP-PCR at the $3^{\prime}$ ends of the CTG repeat in blood samples from different members of the G37 family. The $3^{\prime}$ TPPCR experiment revealed an unexpected pattern of the electrophoretic peak with a large gap, suggesting the presence of several interruptions in the largest CTG repeat allele (Figure 8b). By direct sequencing, we identified (CCGCTG) hexamer interruptions in the repeat. All members of this family carry a stable allele $5^{\prime}-(\mathrm{CTG})_{6}(\mathrm{CCGCTG})_{13}(\mathrm{CTG})_{5}-3^{\prime}$ (Figure $8 \mathrm{c}$ and data not shown). In order to understand the origin of interruption in 
DM1 disease, we genotyped different polymorphic markers in the DM1 locus. First, we showed that a $(\mathrm{CTG})_{6}(\mathrm{CCGCTG})_{13}(\mathrm{CTG})_{5}$ interrupted allele is associated with the $A l u$ insertion polymorphism in the G37 family (Table 2 and data not shown). We completed our haplotype analysis by genotyping other polymorphisms in the DM1 locus (Table 2). Our results showed that the interrupted 37 CTG repeat alleles are associated with haplotype A and are shared by the majority of pure and interrupted DM1 alleles [16,17,29,39-41].

a)
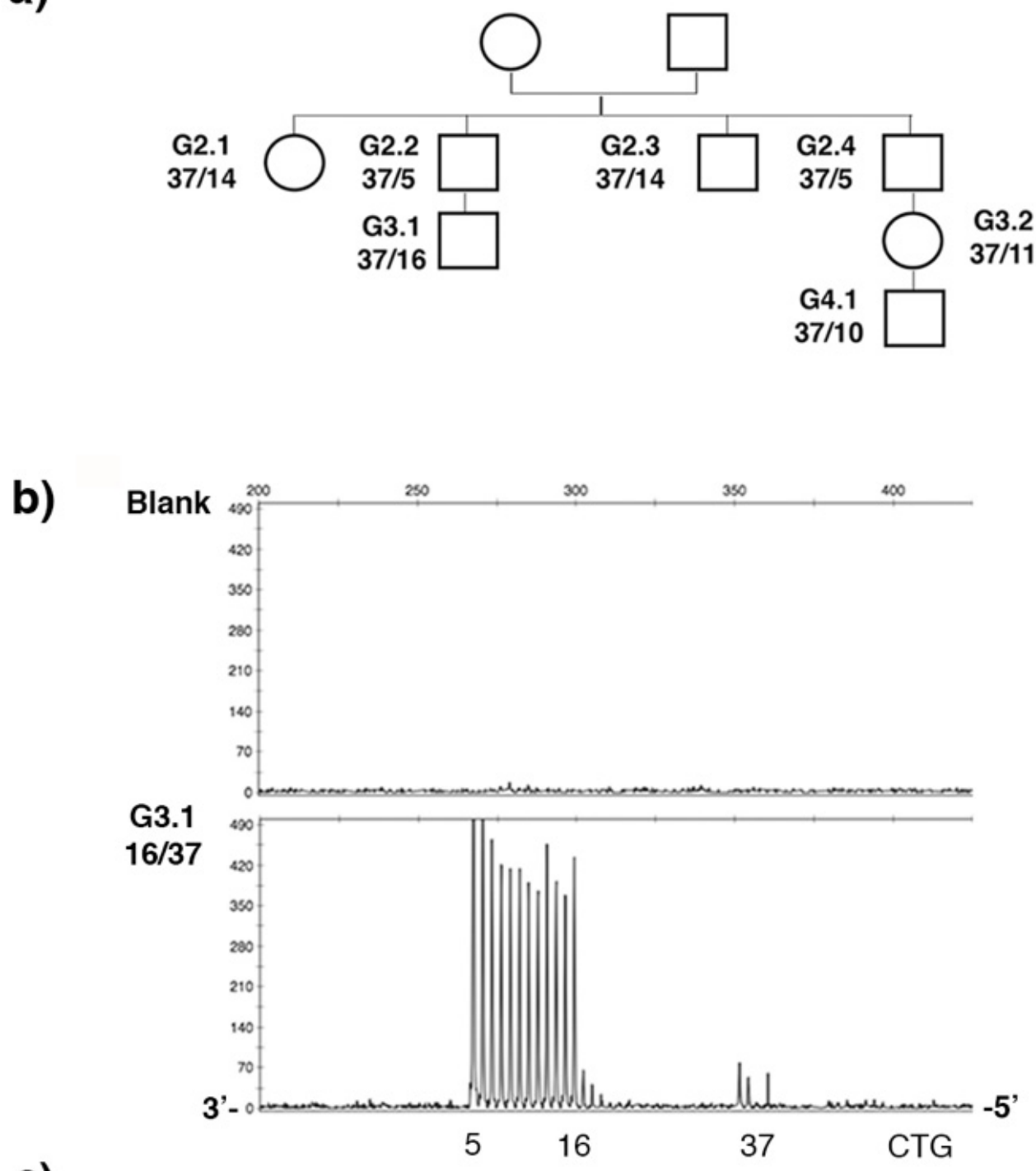

c)

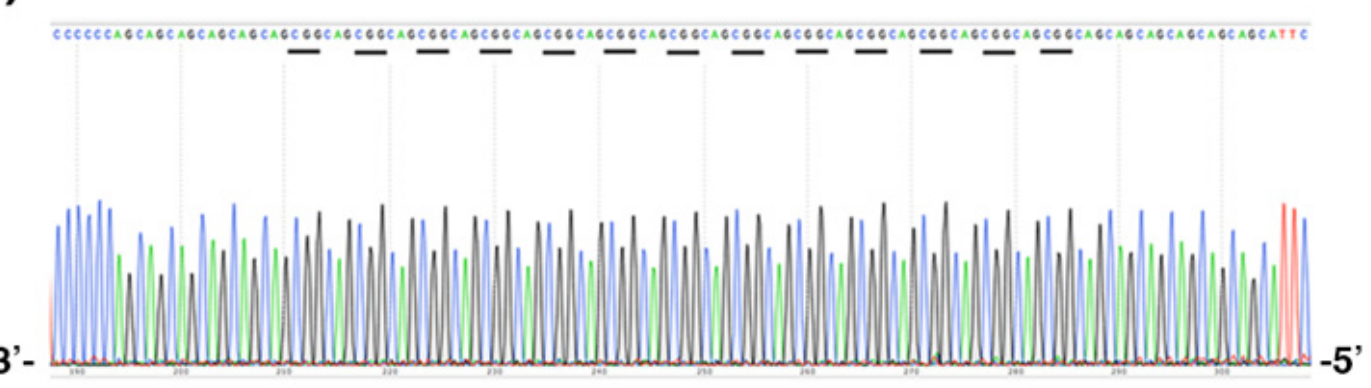

Figure 8. G37 family. (a) Large family carrying DM1 intermediate allele. The CTG repeat length of normal and intermediate alleles are indicated. (b) The $3^{\prime}$ TP-PCR results in a blank and the individual G3.1. The $y$-axis represents the intensity of fluorescence (arbitrary unit) and the $x$-axis represents the fragment length in base pairs. (c) Sequence result in individual G3.1. The CCG interruptions are highlighted. 
Table 2. Association of myotonic dystrophy protein kinase (DMPK) gene-linked haplotype to intermediate $37 \mathrm{CTG}$ repeat allele.

\begin{tabular}{ccccccccc}
\hline Polymorphism & RS2070736 & RS572634 & RS1799894 & $\begin{array}{c}\text { RS4646995 } \\
(\text { Alu } \text { Element })\end{array}$ & RS16939 & RS527221 & RS915915 & CTG \\
\hline Localization & Exon 1 & Intron 4 & Intron 5 & Intron 8 & Intron 9 & Exon 10 & Intron 11 & $3^{\prime}$ UTR \\
\hline G2.2 & $\mathrm{T} / \mathrm{T}$ & $\mathrm{T} / \mathrm{T}$ & $\mathrm{T} / \mathrm{T}$ & Ins $/$ ins & $\mathrm{G} / \mathrm{G}$ & $\mathrm{C} / \mathrm{C}$ & $\mathrm{T} / \mathrm{T}$ & $5 / 37$ \\
\hline $\mathrm{G} 3.1$ & $\mathrm{~T} / \mathrm{T}$ & $\mathrm{T} / \mathrm{T}$ & $\mathrm{T} / \mathrm{T}$ & $\mathrm{Ins} /$ ins & $\mathrm{G} / \mathrm{G}$ & $\mathrm{C} / \mathrm{C}$ & $\mathrm{T} / \mathrm{T}$ & $16 / 37$ \\
\hline DM1 haplotype A & $\mathrm{T}$ & $\mathrm{T}$ & $\mathrm{T}$ & $\mathrm{Ins}$ & $\mathrm{G}$ & $\mathrm{C}$ & $\mathrm{T}$ & $>50$ \\
\hline
\end{tabular}

\section{Discussion}

Genetic counseling for DM1 is very complex due to the highly variable clinical presentation and technical difficulties in determining the size and variant repeat interruptions of the large CTG repeat expansions. For several years, the size of the repeat expansions, the degree of somatic mosaicism and $D M P K$-interrupted alleles have been established as genetic modifiers of DM1 symptoms [3]. A decrease in somatic mosaicism and CTG repeat length is usually associated with a decrease in the severity and age of onset of DM1 symptoms [6,8]. The interruptions are associated with a stabilization of the repeat and a modification in the progression of the DM1 symptoms [16-19,21-23,32]. It is, therefore, crucial to develop a simple and rapid analysis of large CTG repeat expanded sequences to significantly improve our knowledge of DM1. Recently, another study analyzed CTG repeat expansions in different DM1 patients using the penultimate PacBio RSII System. They showed that CCG interruptions are exclusively localized at the end of the sequence in DM1 patients with less than 400 repeats [18]. However, no data were obtained in DM1 patients with larger repeats. Here, we have analyzed, for the first time, two DM1 families carrying CTG repeats ranging from 170 to over 1000 CTG repeats using the Sequel II System. The Sequel II System generates longer reads, enabling higher CCS accuracy, and has higher throughputs than the Sequel and RSII Systems (data not shown and $[18,42,43])$. Here, the Sequel II System and bioinformatic tools give us the ability to simultaneously measure repeat numbers with high resolution, to resolve the complete sequence complex repeat expansions and to measure the degree of somatic mosaicism. We have shown that the Sequel II System allows for sequencing a large repeat expansion as large as 2000 CTG repeats in DM1 patients of the family L with more accuracy than conventional PCR (data not shown). In the family E, we identified a major allele with two de novo CCG interruptions occurring across the E1 and E2.1 paternal transmission by the Sequel II System. Interestingly, the number of interruptions increased from one generation to the next in family E, as previously described in several analyses (Table 3). Using the Sequel II System, we have reported that CCG interruptions at the $3^{\prime}$ end of CTG repeat expansions are associated with CTG stabilization/contraction across generations. Here, the Sequel II System makes it possible to estimate the frequency distribution of the CTG repeat. The level of somatic mosaicism is the highest in L2 and L3 with the largest repeat. In family E, the degree of somatic mosaicism is higher in E1 than in E3, suggesting an age- and size-dependent effect on the somatic mosaicism of the DM1 locus. Strikingly, our new data are consistent with previous studies showing that the dynamics of CTG repeat instability are altered by repeat interruptions and the size and age of DM1 patients using conventional PCR or small pool PCR $[10,16,17,22,44-46]$. The E3 fetus exhibits two major CTG repeat lengths with approximately 170 and 215 CTG repeats, suggesting that the CTG repeat instability is already detectable at the early stage of embryogenesis as previously reported in the literature $[47,48]$. 
Table 3. Summary of DM1 interrupted alleles identified in the literature.

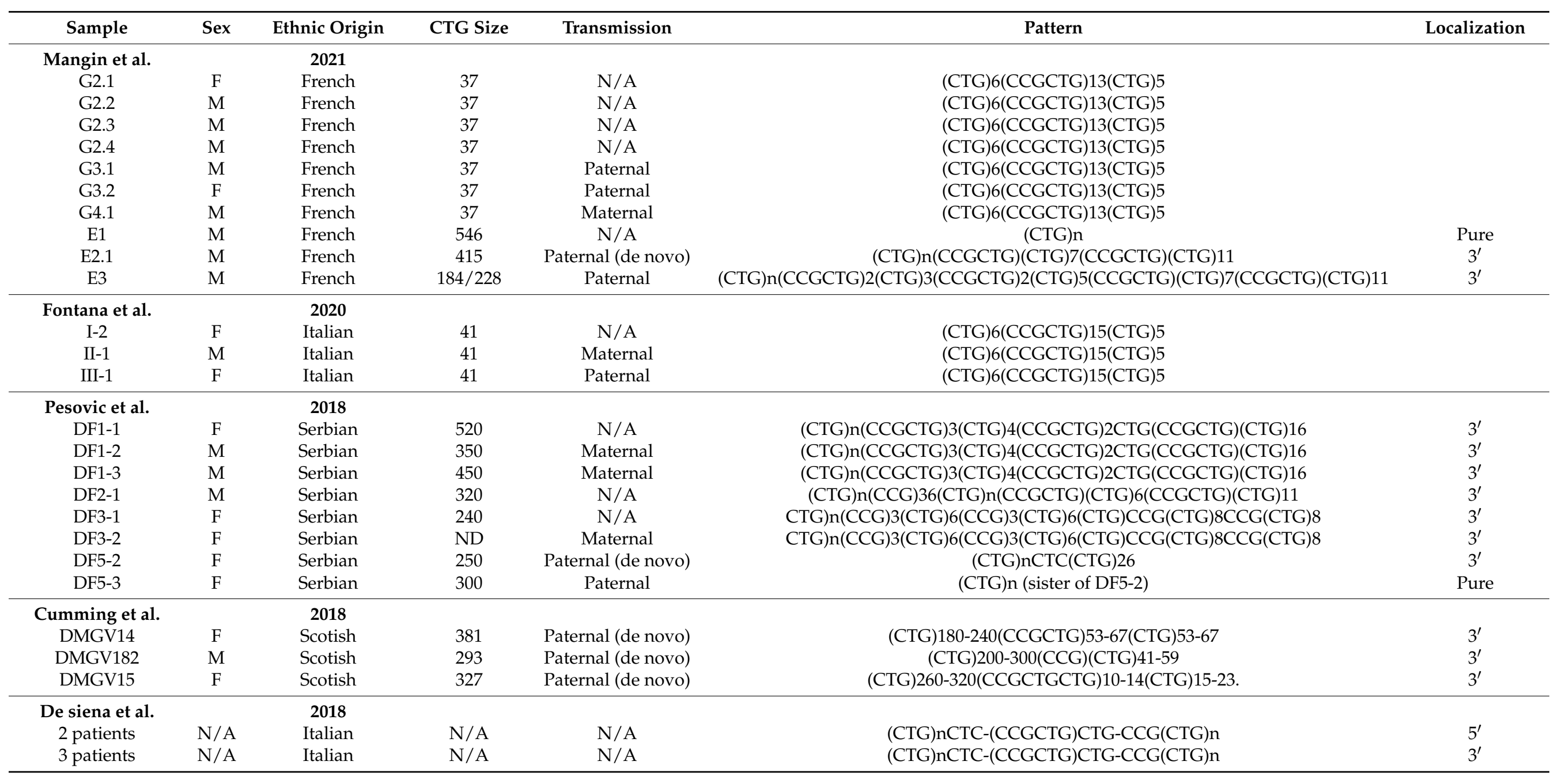


Table 3. Cont.

\begin{tabular}{|c|c|c|c|c|c|c|}
\hline Sample & Sex & Ethnic Origin & CTG Size & Transmission & Pattern & Localization \\
\hline Tomé et al. & & 2018 & & & & \\
\hline A1 & $\mathrm{F}$ & French & 170 & $\mathrm{~N} / \mathrm{A}$ & $(\mathrm{CTG}) \mathrm{n}<32(\mathrm{CAG}) 1(\mathrm{CTG}) \mathrm{n}$ & $5^{\prime}$ \\
\hline A2 & $\mathrm{F}$ & French & 150 & Maternal & $(\mathrm{CTG}) \mathrm{n}<32(\mathrm{CAG}) 1(\mathrm{CTG}) \mathrm{n}$ & $5^{\prime}$ \\
\hline A4.1 & $\mathrm{F}$ & French & 125 & Maternal & $(\mathrm{CTG}) \mathrm{n}<32(\mathrm{CAG}) 1(\mathrm{CTG}) \mathrm{n}$ & $5^{\prime}$ \\
\hline A4. 2 & $\mathrm{~F}$ & French & 130 & Maternal & $(\mathrm{CTG}) \mathrm{n}<32(\mathrm{CAG}) 1(\mathrm{CTG}) \mathrm{n}$ & $5^{\prime}$ \\
\hline A4.3 & $\mathrm{N} / \mathrm{A}$ & French & 125 & Maternal & $(\mathrm{CTG}) \mathrm{n}<32(\mathrm{CAG}) 1(\mathrm{CTG}) \mathrm{n}$ & $5^{\prime}$ \\
\hline B1 & F & French & 365 & $\mathrm{~N} / \mathrm{A}$ & (CTG)11(CCGCTG)(CTG)1(CCGCTG)(CTG)3(CCGCTG)(CTG)n & $5^{\prime}$ \\
\hline B3.1 & $\mathrm{N} / \mathrm{A}$ & French & 300 & Maternal & (CTG)11(CCGCTG)(CTG)1(CCGCTG)(CTG)3(CCGCTG)(CTG)n & $5^{\prime}$ \\
\hline B3.2 & $\mathrm{N} / \mathrm{A}$ & French & 235 & Maternal & (CTG)11(CCGCTG)(CTG)1(CCGCTG)(CTG)3(CCGCTG)(CTG)n & $5^{\prime}$ \\
\hline B3.3 & $\mathrm{N} / \mathrm{A}$ & French & 250 & Maternal & (CTG)11(CCGCTG)(CTG)1(CCGCTG)(CTG)3(CCGCTG)(CTG)n & $5^{\prime}$ \\
\hline Botta et al. & & 2017 & & & & \\
\hline A1 & M & Italian & $1000-1400$ & $\mathrm{~N} / \mathrm{A}$ & (CTG)880-1280(CTG)2(CCGCTG)(CTG)111(CCGCTG)(CTG)3 & $3^{\prime}$ \\
\hline A2 & $\mathrm{F}$ & Italian & $475-640$ & Paternal & (CTG)437-602(CTG)14(CCGCTG)(CTG)17(CCGCTG)(CTG)3 & $3^{\prime}$ \\
\hline A3 & $\mathrm{N} / \mathrm{A}$ & Italian & 500 & Maternal & $\begin{array}{c}\text { (CTG)380(CTG)28(CCGCTG)(CTG)39(CTC)(CTG)36 } \\
\text { (CCGCTG)(CTG)7(CCGCTG)(CTG)3 }\end{array}$ & $3^{\prime}$ \\
\hline B1 & $\mathrm{F}$ & Italian & $740-930$ & $\mathrm{~N} / \mathrm{A}$ & (CTG)699-889(CCGCTG)2(CCG)2(CTG)3(CCGCTG)3(CTG)26 & $3^{\prime}$ \\
\hline $\mathrm{C} 1$ & $\mathrm{~F}$ & Italian & 140 & $\mathrm{~N} / \mathrm{A}$ & $(\mathrm{CTG}) 30(\mathrm{CCG}) 2(\mathrm{CTG}) 2(\mathrm{CCGCTG})(\mathrm{CTG}) 104$ & $5^{\prime}$ \\
\hline $\mathrm{C} 2$ & $\mathrm{~F}$ & Italian & 121 & Maternal & (CTG)28(CCG)2(CTG)2(CCGCTG)(CTG)87 & $5^{\prime}$ \\
\hline $\mathrm{C} 3$ & $\mathrm{~N} / \mathrm{A}$ & Italian & 113 & Maternal & (CTG)31(CCG)2(CTG)2(CCGCTG)(CTG)12(CCGCTG)(CTG)62 & $5^{\prime}$ \\
\hline $\mathrm{D}$ & $\mathrm{F}$ & Italian & $600-700$ & $\mathrm{~N} / \mathrm{A}$ & (CTG)514-614(CTG)68(CCG)9(CTG)9 & $3^{\prime}$ \\
\hline $\mathrm{E}$ & $\mathrm{F}$ & Italian & $500-660$ & $\mathrm{~N} / \mathrm{A}$ & (CTG)404-564(CTG)33(CCGCTG)28(CTG)7 & $3^{\prime}$ \\
\hline $\mathrm{F}$ & M & Italian & 250 & $\mathrm{~N} / \mathrm{A}$ & (CTG)208(CTG)5(CCGCTG)16(CTG)5 & $3^{\prime}$ \\
\hline G & M & Italian & $400-580$ & $\mathrm{~N} / \mathrm{A}$ & (CTG)330-510(CTG)8(CCGCTG)17(CTG)2(CCGCTG)(CTG)24 & $3^{\prime}$ \\
\hline $\mathrm{H}$ & M & Italian & 175 & $\mathrm{~N} / \mathrm{A}$ & $\begin{array}{l}\text { (CTG)133)(CTG)8(CCGCTG)(CTG)4(CCG)2(CTG)(CCG)4 } \\
\text { (CTG)2(CCG)4(CTG)(CCG)2(CTG)2(CCGCTG)(CTG)8 }\end{array}$ & $3^{\prime}$ \\
\hline I & M & Italian & $260-722$ & $\mathrm{~N} / \mathrm{A}$ & $\begin{array}{l}\text { (CTG-188-650(CTG)(CCGCTG)(CTG)(CCGCTG)(CTG)6 } \\
\text { (CCGCTG)(CTG)27(CCGCTG)(CTG)6(CCGCTG)(CTG)21 }\end{array}$ & $3^{\prime}$ \\
\hline Lian et al. & & 2016 & & & & \\
\hline Individu 1 & $\mathrm{~N} / \mathrm{A}$ & ND & 520 & $\mathrm{~N} / \mathrm{A}$ & (CTG)n(CCG)50(CTG)9(CCGCTG)(CTG)6 & $3^{\prime}$ \\
\hline Individu 2 & $\mathrm{~N} / \mathrm{A}$ & ND & $400-480$ & $\mathrm{~N} / \mathrm{A}$ & $\begin{array}{c}\text { (CTG)21(CCGCTG)(CTG)2(CCGCTG)(CTG)2(CCGCTG)(CTG)4(CCGCTG) } \\
\text { (CTG)2(CCGCTG)2(CTG)2(CCGCTGCTG)2(CCGCTG)(CTG)4(CCGCTG)(CTG)n }\end{array}$ & $5^{\prime}$ \\
\hline
\end{tabular}


Table 3. Cont

\begin{tabular}{|c|c|c|c|c|c|c|}
\hline Sample & Sex & Ethnic Origin & CTG Size & Transmission & Pattern & Localization \\
\hline Santoro et al. & & 2015 & & & & \\
\hline Pt58 & $\mathrm{N} / \mathrm{A}$ & Italian & 118 & Maternal & $\begin{array}{c}\text { (CTG)32(CCGCTG)(CTG)(CCGCTG)(CTG)5(CCG)2(CTG)2(CCGCTG)(CTG)4 } \\
\text { (CCGCTG)(CTG)24(CTG)31(CCG)2(CTG)2(CCGCTG)(CTG)21(CCGCTG) } \\
\text { (CTG)33(CCG)2(CTG)2CCGCTC(CTG)4 }\end{array}$ & $3^{\prime}$ \\
\hline Pt59 & $\mathrm{N} / \mathrm{A}$ & Italian & $400-580$ & Paternal & (CCGCTG)7TCGCTG(CCGCTG)7(CTG)20 & $3^{\prime}$ \\
\hline Pt60 & $\mathrm{N} / \mathrm{A}$ & Italian & $450-550$ & Maternal & (CTG)16(CCGCTG)(CTG)1(CCGCTG)4CTG[(CCGCTG)4CCG]2(CCGCTG)5(CTG)22 & $3^{\prime}$ \\
\hline Pt61 & $\mathrm{N} / \mathrm{A}$ & Italian & $475-640$ & Paternal & (CTG)2 G (CTG)9 G (CTG)20(CTG)23TTG(CTG)4 & $3^{\prime}$ \\
\hline Pt62 & $\mathrm{N} / \mathrm{A}$ & Italian & $550-700$ & Paternal & (CTG)5(CCGCTGCTG)46 & $3^{\prime}$ \\
\hline Pt64 & $\mathrm{N} / \mathrm{A}$ & Italian & $600-830$ & Paternal & (CTG)9(CCGCTGCTG)61 & $3^{\prime}$ \\
\hline Pt65 & $\mathrm{N} / \mathrm{A}$ & Italian & $740-930$ & Paternal & (CCGCTG)2(CCG)2(CTG)3(CCGCTG)3(CTG)7(CCGCTG)18 & $3^{\prime}$ \\
\hline Pt66 & $\mathrm{N} / \mathrm{A}$ & Italian & 970 & Maternal & (CTG)12(CCGCTG)(CTG)5(CCGCTG)(CTG)4(CCGCTG)(CTG)4 & $3^{\prime}$ \\
\hline Santoro et al. & & 2013 & & & & \\
\hline pt1/pt62 & $\mathrm{N} / \mathrm{A}$ & Italian & $550-700$ & Paternal & (CTG)2(CCGCTGCTG)5(CCG)(CCGCTGCTG)46(CTG)5 & $3^{\prime}$ \\
\hline pt2/pt64 & $\mathrm{N} / \mathrm{A}$ & Italian & $600-830$ & Paternal & (CTG)(CCGCTGCTG)4(CCG)(CCGCTGCTG)61(CTG)9 & $3^{\prime}$ \\
\hline pt3 & $\mathrm{N} / \mathrm{A}$ & Italian & 65 & $\mathrm{~N} / \mathrm{A}$ & $(\mathrm{CTG})(\mathrm{CTG} / \mathrm{CCG})(\mathrm{CTG}) 2(\mathrm{CTG} / \mathrm{CCG})(\mathrm{CCGCTGCTG}) 5(\mathrm{CTG}) 3$ & $3^{\prime}$ \\
\hline pt4 & $\mathrm{N} / \mathrm{A}$ & Italian & 900 & $\mathrm{~N} / \mathrm{A}$ & $\begin{array}{c}\text { (CTG)16(CCGCTG)(CTG)3(CCGCTG)(CTG)7(CCGCTG) } \\
\text { (CTG)4(CCGCTG)(CTG)(CCGCTG)(CTG)(CCGCTG)(CTG)7 }\end{array}$ & $3^{\prime}$ \\
\hline $\begin{array}{c}\text { Addis et al. } \\
\text { AA }\end{array}$ & $\mathrm{N} / \mathrm{A}$ & $\begin{array}{c}2012 \\
\text { Sardinian }\end{array}$ & $\mathrm{N} / \mathrm{A}$ & $\mathrm{N} / \mathrm{A}$ & (CTG)3(CCGCTG)(CTG)2(CCG)CT en 3' & $3^{\prime}$ \\
\hline Radvansky et al. & & 2011 & & & & \\
\hline Sample 7 & $\mathrm{~N} / \mathrm{A}$ & Czech & $\mathrm{N} / \mathrm{A}$ & $\mathrm{N} / \mathrm{A}$ & $(\mathrm{CTG}) \mathrm{n}(\mathrm{CCG}) 38(\mathrm{CTG}) 22$ & $3^{\prime}$ \\
\hline Sample 8 & $\mathrm{~N} / \mathrm{A}$ & Czech & $\mathrm{N} / \mathrm{A}$ & $\mathrm{N} / \mathrm{A}$ & (CTG)nCTC(CTG)9(CCGCTG)2(CTG)2(CCGCTG)(CTG)4(CCGCTG)(CTG)12 & $3^{\prime}$ \\
\hline Sample 9 & $\mathrm{~N} / \mathrm{A}$ & Czech & 43 & $\mathrm{~N} / \mathrm{A}$ & (CTG)6(CCGCTG)16(CTG)5 & \\
\hline Sample 10 & $\mathrm{~N} / \mathrm{A}$ & Czech & 43 & $\mathrm{~N} / \mathrm{A}$ & (CTG)6(CCGCTG)16(CTG)5 & \\
\hline Sample 11 & $\mathrm{~N} / \mathrm{A}$ & Czech & 39 & $\mathrm{~N} / \mathrm{A}$ & (CTG)6(CCGCTG)13(CTG)5 & \\
\hline Sample 12 & $\mathrm{~N} / \mathrm{A}$ & Czech & 41 & $\mathrm{~N} / \mathrm{A}$ & (CTG)6(CCGCTG)15(CTG)5 & \\
\hline Musova et al. & & 2009 & & & & \\
\hline A-1 & $\mathrm{N} / \mathrm{A}$ & Czech & 230 & Maternal & (CTG)n(CTC)(CTG)9(CCGCTG)2(CTG)2(CCGCTG)(CTG)4(CCGCTG)(CTG)12 & $3^{\prime}$ \\
\hline A-2 & $\mathrm{F}$ & Czech & 300 & Paternal & (CTG)n(CTC)(CTG)9(CCGCTG)2(CTG)2(CCGCTG)(CTG)4(CCGCTG)(CTG)12 & $3^{\prime}$ \\
\hline A-3 & $\mathrm{F}$ & Czech & $400-500$ & Paternal & (CTG)n(CTC)(CTG)7(CCGCTG)(CTG)4(CCGCTG)(CTG)4(CCGCTG)(CTG)12 & $3^{\prime}$ \\
\hline
\end{tabular}


Table 3. Cont

\begin{tabular}{|c|c|c|c|c|c|c|}
\hline Sample & Sex & Ethnic Origin & CTG Size & Transmission & Pattern & Localization \\
\hline A-4 & M & Czech & $600-800$ & $\mathrm{~N} / \mathrm{A}$ & (CTG)n(CTC)(CTG)9(CCGCTG)(CTG)4(CCGCTG)(CTG)4(CCGCTG)(CTG)12 & $3^{\prime}$ \\
\hline A-5 & $\mathrm{F}$ & Czech & $450-650$ & $\mathrm{~N} / \mathrm{A}$ & (CTG)n(CTC)(CTG)9(CCGCTGCTG)6(CTG)8 & $3^{\prime}$ \\
\hline A-6 & $\mathrm{F}$ & Czech & $650-750$ & Maternal & (CTG)n(CTC)(CTG)9(CCGCTGCTG)5(CTG)8 & $3^{\prime}$ \\
\hline B-1 & M & Czech & 450 & $\mathrm{~N} / \mathrm{A}$ & (CTG)n(CCGCTG)39(CCG)(CCGCTG)3(CTG)18 & $3^{\prime}$ \\
\hline $\mathrm{B}-2$ & M & Czech & 400 & Paternal & (CTG)n(CCGCTG)37(CCG)12(CTG)(CCGCTG)(CTG)10 & $3^{\prime}$ \\
\hline $\mathrm{C}$ & $\mathrm{F}$ & Czech & 700 & $\mathrm{~N} / \mathrm{A}$ & $\begin{array}{c}\text { (CTG)n(CCGCTG)2(CCG)8CTG(CCG)6CTG(CCG)6(CTG)(CCGCTG) } \\
\text { (CCG)(CCGCTG)4(CCG)(CCGCTG)4(CTG)(CCGCTG)4(CTG) } \\
\text { (CCGCTG)4(CCG)(CCGCTG)3(CTG)3(CCGCTG)2(CTG)10 }\end{array}$ & $3^{\prime}$ \\
\hline $\mathrm{D}$ & M & Czech & 37 & $\mathrm{~N} / \mathrm{A}$ & (CTG)6(CCGCTG)13(CTG)5 & \\
\hline E-1 & M & Czech & 43 & Paternal & (CTG)6(CCGCTG)16(CTG)5 & \\
\hline $\mathrm{E}-2$ & M & Czech & 43 & $\mathrm{~N} / \mathrm{A}$ & (CTG)6(CCGCTG)16(CTG)5 & \\
\hline $\begin{array}{l}\text { Leeflang et al. } \\
\qquad 5048\end{array}$ & $\mathrm{~N} / \mathrm{A}$ & $\begin{array}{c}1995 \\
\text { Caucasian }\end{array}$ & 37 & $\mathrm{~N} / \mathrm{A}$ & (CTG)4(CCGCTG)16(CTG)1 Alu Haplotype & \\
\hline Braida et al. & & 2010 & & & & \\
\hline III-9 & M & Dutch & $\begin{array}{l}\text { 225/DM1- } \\
\text { charcot }\end{array}$ & $\mathrm{N} / \mathrm{A}$ & $\begin{array}{c}\text { mutant allele: (CTG)n(GGC)3G(CCG)20(CCGCTG)14(CTG)35 and normal allele: } \\
\text { (CTG)5(CCGCTG)14(CTG) }\end{array}$ & $3^{\prime}$ \\
\hline IV-12 & M & Dutch & 38/Normal & Paternal & (CTG)5(CCGCTG)14(CTG) & \\
\hline $\begin{array}{l}\text { DM1-Charcot } \\
\text { family }\end{array}$ & $\mathrm{N} / \mathrm{A}$ & Dutch & $500<\mathrm{CTG}>200$ & $\mathrm{~N} / \mathrm{A}$ & (CTG)n(GGC)3G(CCG)20(CCGCTG)14(CTG)35 & $3^{\prime}$ \\
\hline DM1-UC1 & $\mathrm{F}$ & French & $\mathrm{N} / \mathrm{A}$ & $\mathrm{N} / \mathrm{A}$ & (CTG)n(CNG)(CTG)n(CNG)(CCGCTG)17(CTG)15 & $3^{\prime}$ \\
\hline DM1-UC2 & $\mathrm{M}$ & French & $\mathrm{N} / \mathrm{A}$ & Maternal & (CTG)222(CCG)5(CTG)5(CCG)5(CTG)5(CCG)5(CCGCTG)23(CTG)14 & $3^{\prime}$ \\
\hline DM1-UC3 & $\mathrm{N} / \mathrm{A}$ & French & $\mathrm{N} / \mathrm{A}$ & $\mathrm{N} / \mathrm{A}$ & $\begin{array}{l}\text { (CTG)425(CCGCTG)4(CTG)2(CCGCTG)4(CTG)2(CCGCTG) } 4 \\
\text { (CTG)4(CCGCTG)(CTG)4(CCGCTG)(CTG)4(CCGCTG)(CTG) } 14\end{array}$ & $3^{\prime}$ \\
\hline DM1-UC4 & $\mathrm{N} / \mathrm{A}$ & French & $\mathrm{N} / \mathrm{A}$ & $\mathrm{N} / \mathrm{A}$ & (CTG)318(CCGCTG)19(CTG)13 & $3^{\prime}$ \\
\hline DM1-UC5 & $\mathrm{N} / \mathrm{A}$ & French & $\mathrm{N} / \mathrm{A}$ & $\mathrm{N} / \mathrm{A}$ & $\begin{array}{l}\text { (CTG)412(CCG)5(CTG)5(CCGCTG)(CCG)5(CTG)5(CCGCTG)3(CTG)4(CCGCTG)3 } \\
\text { (CTG)4(CCGCTG)3(CTG)4(CCGCTG)(CTG)5(CCGCTG)(CTG)5(CCGCTG)(CTG)5 }\end{array}$ & $3^{\prime}$ \\
\hline DM1-UC6 & $\mathrm{N} / \mathrm{A}$ & French & $\mathrm{N} / \mathrm{A}$ & $\mathrm{N} / \mathrm{A}$ & $\begin{array}{l}\text { (CTG)516(CCG)3(CTG)(CCG)3(CTG)(CCG)2(CTG)5(CCGCTG)(CTG)5(CCGCTG) } \\
\text { (CTG)5(CCG)3(CTG)6(CCG)3(CTG)6(CCG)3(CTG)6(CCG)3(CTG)6(CTG)26 }\end{array}$ & $3^{\prime}$ \\
\hline DM1-UC7 & $\mathrm{N} / \mathrm{A}$ & French & 41 & $\mathrm{~N} / \mathrm{A}$ & (CTG)6(CCGCTG)15(CTG)5 & \\
\hline DM1-UC8 & $\mathrm{N} / \mathrm{A}$ & French & $\mathrm{N} / \mathrm{A}$ & $\mathrm{N} / \mathrm{A}$ & $\begin{array}{l}\text { (CTG)225(CCGCTG)(CTG)7(CCGCTG)(CTG)7(CCG)3(CTG)8(CCG)3 } \\
\text { (CTG)8(CCG)3(CTG)8(CCG)3(CTG)8(CTG)2(CCGCTG)(CTG)8 }\end{array}$ & $3^{\prime}$ \\
\hline DM1-UC9 & $\mathrm{N} / \mathrm{A}$ & French & 396 & $\mathrm{~N} / \mathrm{A}$ & (CTG)n pure et délétion 10bp en $3^{\prime}$ & $\mathrm{N} / \mathrm{A}$ \\
\hline DM1-UC10 & $\mathrm{M}$ & French & $\mathrm{N} / \mathrm{A}$ & $\mathrm{N} / \mathrm{A}$ & (CTG)166(CCGCTG)31(CTG)58 & $3^{\prime}$ \\
\hline DM1-UC11 & $\mathrm{N} / \mathrm{A}$ & French & $\mathrm{N} / \mathrm{A}$ & Paternal & (CTG)105(CCGCTG)119(CTG)8 & $3^{\prime}$ \\
\hline
\end{tabular}


Table 3. Cont.

\begin{tabular}{|c|c|c|c|c|c|c|}
\hline Sample & Sex & Ethnic Origin & CTG Size & Transmission & Pattern & Localization \\
\hline Leferink et al. & & 2019 & & & & \\
\hline USN04034 & $\mathrm{N} / \mathrm{A}$ & Dutch & $>150$ & $\mathrm{~N} / \mathrm{A}$ & (CTG)n(CCGCTG) 100(CTG)n & $3^{\prime}$ \\
\hline USN08692 & $\mathrm{N} / \mathrm{A}$ & Dutch & $>150$ & $\mathrm{~N} / \mathrm{A}$ & (CTG)n(CCGCTG)114(CTG)n & $3^{\prime}$ \\
\hline USN01084 & $\mathrm{N} / \mathrm{A}$ & Dutch & $>150$ & $\mathrm{~N} / \mathrm{A}$ & (CTG)n(CCGCTG)167(CTG)n & $3^{\prime}$ \\
\hline USN01299 & $\mathrm{N} / \mathrm{A}$ & Dutch & $>150$ & $\mathrm{~N} / \mathrm{A}$ & (CTG)n(CCGCTG)37(CTG)n & $3^{\prime}$ \\
\hline $\begin{array}{c}\text { Ballester-Lopez } \\
\text { et al. }\end{array}$ & & 2020 & & & & \\
\hline Patient 1 & $\mathrm{~F}$ & Spanish & 319 & $\mathrm{~N} / \mathrm{A}$ & (CTG)n(CCGCTG)(CTG)16(CCGCTG)(CTG)n & $\mathrm{N} / \mathrm{A}$ \\
\hline Patient 2 & $\mathrm{~F}$ & Spanish & 241 & $\mathrm{~N} / \mathrm{A}$ & (CTG)n(CCGCTG)(CTG)8(CCG)(CCGCTG)(CTG)(CCGCTG)(CTG)3(CCGCTG)(CTG)n & $\mathrm{N} / \mathrm{A}$ \\
\hline Patient 3 & $\mathrm{~F}$ & Spanish & 368 & $\mathrm{~N} / \mathrm{A}$ & (CTG)n(CCGCTG)3(CTG)3(CCGCTG)3(CTG)3(CCGCTG)2(CTG)n & $\mathrm{N} / \mathrm{A}$ \\
\hline Patient 4 & M & Spanish & 222 & Maternal & (CTG)n(CCGCTG)(CTG)8(CCG)(CCGCTG)(CTG)(CCGCTG)(CTG)3(CCGCTG)(CTG)n & $\mathrm{N} / \mathrm{A}$ \\
\hline Patient 5 & $\mathrm{~F}$ & Spanish & 547 & Maternal & (CTG)n(CCGCTG)3(CTG)(CCG)2(CCGCTG)2(CTG)3(CCGCTG)2(CTG)n & $\mathrm{N} / \mathrm{A}$ \\
\hline
\end{tabular}


The Sequel II System successfully sequences CTG repeat expansions in our DM1 families. This new technology is a straightforward way to detect clinically significant repeat changes and estimate the size of the repeat in blood using targeted sequencing with PacBio SMRT sequencing. Despite the advanced PacBio technology, amplicon-based long-read sequencing still depends on PCR and the inherent bias towards preferential amplification of smaller repeats. To overcome this limitation, amplification-free targeted sequencing has been first described in a Fuchs' endothelial corneal dystrophy-associated Transcription Factor 4 (TCF4) CTG triplet repeat [49]. The procedure consists of sequencing targeted genomic regions, without amplification, on a PacBio System by using Clustered Regularly Interspaced Short Palindromic Repeat (CRISPR)-Cas9 enrichment technology [38]. This approach should improve the analysis of CTG repeat expansions and somatic mosaicism in DM1 and also in other TNR diseases.

As noted above, we have identified family $\mathrm{E}$ with de novo CCG interruptions at the $3^{\prime}$ end in the CTG repeat expansion (Table 1). The percentage of interrupted expanded alleles has been estimated at $3-8 \%$ in the non-African DM1 population (Table 3 and [16-20,22,24-32]). To date, the origin of the interruptions remains very obscure. In our study, we reported a normal interrupted allele with 37 stable CTG repeats $\left(5^{\prime}-\right.$ $\left.(\mathrm{CTG})_{6}(\mathrm{CCGCTG})_{13}(\mathrm{CTG})_{5}-3^{\prime}\right)$ associated with haplotype A in a large French family (two paternal transmissions and one maternal transmission). Our data suggest that the size and interruption pattern of this allele remain stable through generations. Two other analyses showed that stable CCG-interrupted 37 or 41 repeat alleles share a common haplotype A with DM1 mutation $[17,29]$. The DM1 haplotype A was also found in DM1 patients with interrupted expanded alleles, suggesting that the normal allele might be a source of imperfect expanded alleles found in less than 10\% of DM1 patients [16,17,29,39-41]. However, the profile/type of interrupted alleles found in patients carrying $37,38,41,43$ or more than 50 repeats is extremely variable within DM1 families and also between DM1 families (Table 3), which does not suggest any haplotype specificity of the interrupted alleles. In addition, stabilization of a repeat by interruptions does not favor the hypothesis of an interrupted normal allele as the source of the interrupted expanded allele in the DM1 population $[10,16,17,22,31]$. The heterogeneity of the number and type of interruptions observed in the interrupted expanded alleles suggests new mechanisms leading to base substitution in the sequence and/or duplication of existing interruptions in the repeated sequence (Table 3). The emergence of interruptions can be caused by multiple processes including spontaneous DNA damage, DNA repair and DNA polymerase errors occurring in germ cells and somatic cells throughout embryogenesis and the lifetime of DM1 patients.

To conclude, we used the latest generation of the long-read sequencing system in DM1 patients with more than 1000 CTG repeats that allows detection of a single nucleotide change in the sequence and estimates the size of the large repeated sequence and somatic mosaicism at the same time. SMRT sequencing opens new avenues for DM1 disease and will provide a better understanding of the clinical and genetic variability observed in DM1 through global analysis. Growth in users of SMRT sequencing and reduction in its price will enable SMRT sequencing to be implemented as a routine molecular diagnostic method offering the best diagnostics and prognosis for patients in the near future. Our study reinforced the idea that interrupted alleles do not originate from an ancestral/normal allele but from unknown mechanisms occurring both in the germline and in somatic cells.

\section{Materials and Methods}

\subsection{Patient Recruitment}

Individuals from family G37 and DM1 patients were recruited by the Genetics Department of the Hospital of Nantes, the Genetics Department of the Hospital of Toulouse, the Genetics Department of the Necker-Enfants Malades Hospital and the DM-Scope registry [50] in France. Major clinical data are available for DM1 patients from family E. Each patient gave informed consent stating that their DNA samples could be used for research 
purposes. The individuals A4.1, 1201, B2 and 5289 described in Tomé et al. and analyzed by SMRT sequencing in this study are not related to each other [16].

\subsection{CTG Repeat Amplification}

To precisely estimate the inherited CTG repeat length in all individuals, $5 \mathrm{ng}$ of DNA from blood or trophoblast was amplified in a $25-\mu \mathrm{L}$ reaction using $0.4 \mu \mathrm{M}$ ST300F $\left(5^{\prime}-\right.$ GAACTGTCTTCGACTCCGGG-3') and ST300R (5'-GCACTTTGCGAACCAACGAT-3') primers, $1 \times$ Custom master mix (Thermo Fisher Scientific, Courtaboeuf, France) and 0.04U Thermoperfect Taq polymerase (Peak International Products b.v, LZ Eerbeek, Netherlands). The following cycling conditions were used: $5 \mathrm{~min}$ at $96{ }^{\circ} \mathrm{C} ; 45 \mathrm{~s}$ at $96{ }^{\circ} \mathrm{C}, 30 \mathrm{~s}$ at $60^{\circ} \mathrm{C}$ and $3 \mathrm{~min}$ at $72{ }^{\circ} \mathrm{C}$ ( 30 cycles); $1 \mathrm{~min}$ at $60^{\circ} \mathrm{C}$ and $10 \mathrm{~min}$ at $72{ }^{\circ} \mathrm{C}$ ( 1 cycle). PCR product was mixed with orange DNA loading dye and run on a $1.5 \%$ agarose gel at $120 \mathrm{~V}$. The size of the PCR products was measured using Bio-Rad's Image Lab software. The approximate number of triplet repeats can be obtained by subtracting $361 \mathrm{bp}$ (corresponding to the size of $5^{\prime}$ and $3^{\prime}$ flanking regions) from the PCR product length divided by 3 .

\subsection{3'Triplet-Primed PCR (TP-PCR)}

To analyze the purity of the CTG repeat tract at the $3^{\prime}$ end CTG repeat array, TP-PCR was performed on both strands of the CTG repeat [32,34]. The $3^{\prime}$ end CTG repeat was amplified using the primer downstream of the CTG repeat Somy4R-FAM (5'-FAM-CGG GTT TGG CAA AAG CAA ATT TCC CGA-3'), P3R (5'-TAC GCA TCC CAG TTT GAG ACG-3') and P4CTG (5'-TAC GCA TCC CAG TTT GAG ACG TGC TGC TGC TGC TGC T-3') primers as described in Tomé et al. [33]. Briefly, 20-100 ng of DNA from blood and trophoblast was amplified using $0.4 \mu \mathrm{M}$ Somy4R-FAM and P3R primers and $0.04 \mu \mathrm{M}$ P4CTG primer, $1 \times$ Custom master mix (Thermo Fisher Scientific, Courtaboeuf, France) and 0.06U Thermoperfect Taq polymerase (Peak International Products b.v, LZ Eerbeek, Netherlands)). The conditions of TP-PCR were as follows: denaturation at $94{ }^{\circ} \mathrm{C}$ for $5 \mathrm{~min}$ followed by 30 cycles at $94{ }^{\circ} \mathrm{C}$ for $1 \mathrm{~min}, 68^{\circ} \mathrm{C}$ for $1 \mathrm{~min} 30 \mathrm{~s}$ and at $72{ }^{\circ} \mathrm{C}$ for $2 \mathrm{~min}$ and a final extension step at $72{ }^{\circ} \mathrm{C}$ for $10 \mathrm{~min}$ ( 1 cycle). The amplified product was analyzed using a 3500 XL genetic analyzer (Applied Biosystems, Foster City, CA, USA) and Gene Mapper software (Thermo Fisher Scientific, Courtaboeuf, France).

\subsection{CTG Repeat Sequencing}

CTG repeat tracts were sequenced as described in Tomé et al. [16]. Briefly, normal and expanded CTG repeat alleles were amplified by PCR using ST300F and ST300R primers and sequenced on a 3500 XL genetic analyzer (Applied Biosystems, Foster City, CA, USA). When it was necessary, purified PCR products were cloned using a TOPO-TA cloning kit (Thermo Fisher Scientific, Courtaboeuf, France) and each clone was sequenced using M13F (-20) 5'-GTA AAA CGA CGG CCA G-3' and M13R 5' CAG-GAA-ACA-GCT-ATG-AC-3' primers. MacVector software was used to analyze the sequence.

\subsection{Sequel II System from PacBio (PacBio and Sequel Are Trademarks of Pacific Biosciences)}

Generation of amplicons with the CTG repeat expansion. Normal and expanded CTG repeat alleles were amplified by PCR using barcoded ST300-F and ST300-R primers (Table 4). After amplification, the PCR products for each sample were pooled and purified using the 0.5X (DM1 patients <900 CTG) or 0.45X (DM1 patients >1000 CTG) AMPure PB beads (Pacific Biosciences, Menlo Park, CA, USA) clean-up procedure. AMPure PB beads were used to remove unbound primers and the PCR product corresponding to DMPK normal allele. The PCR product corresponding to expanded alleles was quantified by Qubit fluorometric quantification (Thermo Fischer Scientific, Courtaboeuf, France). The quality of each purified PCR product pool was tested on an agarose gel of $1.5 \%$. 
Table 4. Primers used for long-read sequencing.

\begin{tabular}{|c|c|c|c|c|c|c|c|c|c|}
\hline Patients & $\begin{array}{c}\text { Age } \\
\text { (year) }\end{array}$ & Interruptions & $\begin{array}{l}\text { PCR Product } \\
\text { (bp) }\end{array}$ & $5^{\prime}$ Modification & Buffer Sequence & Barcode Name & Barcode & Primer ST-barcoded-300-F & Primer ST-barcoded-300-R \\
\hline E1 & 56 & Yes (CCG) & 2551 & Phosphate & GGTAG & BC1018_Forward & TCACGTGCTCACTGTG & $\begin{array}{l}\text { GGTAGTCACGTGCT } \\
\text { CACTGTGGAACTGT } \\
\text { CTTCGACTCCGGG }\end{array}$ & $\begin{array}{l}\text { GGTAGTCACGTGCT } \\
\text { CACTGTGGCACTTT } \\
\text { GCGAACCAACGAT }\end{array}$ \\
\hline E2.1 & 29 & Yes (CCG) & 1864 & Phosphate & GGTAG & BC1019_Forward & ACACACTCTATCAGAT & $\begin{array}{l}\text { GGTAGACACACTCT } \\
\text { ATCAGATGAACTGT } \\
\text { CTTCGACTCCGGG }\end{array}$ & $\begin{array}{l}\text { GGTAGACACACTCT } \\
\text { ATCAGATGCACTTT } \\
\text { GCGAACCAACGAT }\end{array}$ \\
\hline E3 & 0 & Yes (CCG) & 1150 & Phosphate & GGTAG & BC1020_Forward & CACGACACGACGATGT & $\begin{array}{c}\text { GGTAGCACGACACG } \\
\text { ACGATGTGAACTGT } \\
\text { CTTCGACTCCGGG }\end{array}$ & $\begin{array}{l}\text { GGTAGCACGACACG } \\
\text { ACGATGTGCACTTT } \\
\text { GCGAACCAACGAT }\end{array}$ \\
\hline L2 & 31 & No & $>5000$ & Phosphate & GGTAG & BC1012_Forward & ACACTAGATCGCGTGT & $\begin{array}{l}\text { GGTAGACACTAGAT } \\
\text { CGCGTGTGAACTGT } \\
\text { CTTCGACTCCGGG }\end{array}$ & $\begin{array}{l}\text { GGTAGACACTAGAT } \\
\text { CGCGTGTGCACTTT } \\
\text { GCGAACCAACGAT }\end{array}$ \\
\hline L3 & 26 & No & $>5000$ & Phosphate & GGTAG & BC1013_Forward & CTCTCGCATACGCGAG & $\begin{array}{l}\text { GGTAGCTCTCGCAT } \\
\text { ACGCGAGGAACTGT } \\
\text { CTTCGACTCCGGG }\end{array}$ & $\begin{array}{l}\text { GGTAGCTCTCGCAT } \\
\text { ACGCGAGGCACTTT } \\
\text { GCGAACCAACGAT }\end{array}$ \\
\hline A4.1 & 32 & Yes (CAG) & 760 & Phosphate & GGTAG & BC1016_Forward & CATAGAGAGATAGTAT & $\begin{array}{l}\text { GGTAGCATAGAGAG } \\
\text { ATAGTATGAACTGT } \\
\text { CTTCGACTCCGGG }\end{array}$ & $\begin{array}{l}\text { GGTAGCATAGAGAG } \\
\text { ATAGTATGCACTTT } \\
\text { GCGAACCAACGAT }\end{array}$ \\
\hline 1201 & 32 & No & 796 & Phosphate & GGTAG & BC1017_Forward & CACACGCGCGCTATAT & $\begin{array}{l}\text { GGTAGCACACGCGC } \\
\text { GCTATATGAACTGT } \\
\text { CTTCGACTCCGGG }\end{array}$ & $\begin{array}{l}\text { GGTAGCACACGCGC } \\
\text { GCTATATGCACTTT } \\
\text { GCGAACCAACGAT }\end{array}$ \\
\hline B2 & 33 & Yes (CCG) & 1291 & Phosphate & GGTAG & BC1014_Forward & CTCACTACGCGCGCGT & $\begin{array}{l}\text { GGTAGCTCACTACG } \\
\text { CGCGCGTGAACTGT } \\
\text { CTTCGACTCCGGG }\end{array}$ & $\begin{array}{l}\text { GGTAGCTCACTACG } \\
\text { CGCGCGTGCACTTT } \\
\text { GCGAACCAACGAT }\end{array}$ \\
\hline 5289 & 37 & No & 1141 & Phosphate & GGTAG & BC1015_Forward & CGCATGACACGTGTGT & $\begin{array}{l}\text { GGTAGCGCATGACA } \\
\text { CGTGTGTGAACTGT } \\
\text { CTTCGACTCCGGG }\end{array}$ & $\begin{array}{l}\text { GGTAGCGCATGACA } \\
\text { CGTGTGTGCACTTT } \\
\text { GCGAACCAACGAT }\end{array}$ \\
\hline
\end{tabular}


Construction and sequencing of SMRTbell libraries. SMRTbell libraries were prepared using the SMRTbell Express Template Prep Kit 2.0, following PacBio's "Procedure \& Checklist-Preparing SMRTbell Libraries using PacBio Barcoded Universal Primers for Multiplexing Amplicons", starting on page 11 [51]. Binding was performed with the Sequel II Binding Kit 2.1. Sequel II System run conditions included a 1-h pre-extension and 25-h movie time per SMRT Cell.

Bioinformatic analyses. Single molecule circular consensus sequences (CCS or HiFi reads) were generated from raw sequencing data using CCS version 5.0.0 (https:/ / github. $\mathrm{com} /$ PacificBiosciences/ccs). Consensus reads were filtered for sequences having $\geq 3$ passes and a minimum mean read accuracy of QV20, and sample reads were demultiplexed using lima version 2.0.1. HiFi reads were aligned to the reference using pbmm2 version 1.4.0. Repeat motifs were counted and clustered by allele using RepeatAnalysisTools (https: //github.com/PacificBiosciences/apps-scripts/tree/master/RepeatAnalysisTools).

\subsection{Haplotype Analyses}

Polymorphisms flanking the CTG repeat expansion were genotyped using targeted re-sequencing developed by the Genomic Platform of the Imagine Institute. Briefly, $1 \mu \mathrm{g}$ of genomic DNA was prepared and quantified by Qubit fluorometric quantification (Thermo Fischer Scientific, Courtaboeuf, France). In order to sequence the DM1 locus, a cosmid with a large human fragment of $45 \mathrm{~kb}$ containing the DMPK gene with 55 repeats and the flanking sequence was used to target the region of interest. The DM1 locus was sequenced using Illumina sequencing technology.

Author Contributions: L.M., M.N., P.B. and S.M. identified patients and collected and provided the DNA samples. A.M. performed the characterization of CTG repeat expansion using conventional methods (PCR, TP-PCR, short-read sequencing). Y.-C.T., J.Z., J.H., C.H. and S.T. conducted long-read targeted sequencing experiments. L.d.P. and S.T. wrote the manuscript. G.G. and S.T. supervised and conceived the study. All authors have read and agreed to the published version of the manuscript.

Funding: This work was supported by the Institut National de la Santé et de la Recherche Médicale; Université Paris Descartes; Association Française contre les Myopathies (AFM) Telethon (project numbers 16331 and 19757) and the 2019 Targeted Sequencing SMRT Grant. This program received a state subsidy managed by the National Research Agency under the "Investments for the Future" program bearing the reference ANR-10-IAHU-01.

Institutional Review Board Statement: The study was conducted according to the guidelines of the Declaration of Helsinki. Blood samples were collected accordingly following the consent procedure that was approved by the national ethic committee CCTIRS (Advisory Committee on Information Processing in Material Research in the Field of Health); adult patients or legal guardians received an information letter presenting the study.

Informed Consent Statement: Informed consent was obtained from all subjects involved in the study.

Data Availability Statement: All the data necessary to evaluate the conclusions in this study are present in the article. Additional data related to this paper may be requested from the authors.

Acknowledgments: The authors would like to thank the DM1 patients, colleagues at the Imagine Institute and Myology center and M. Gomes Pereira and E. Letoriellec for helpful discussions and comments. We specially thank Christine Bole, Patrick Nitschké (Genomic and Bioinformatic platforms, Imagine Institute), Benoit Arveiler (Genetics Department of the Hospital of Toulouse), Y. Pereon and A. Magot (Genetics Department of the Hospital of Nantes) and Lori Aro, Deborah Moine, David Stucki and Mozhgan Novbakhtian (PacBio) for their active involvement in this project. S. Tomé would like to warmly thank Pietro and Sylvie Tomé for their helpful discussion and support in this project.

Conflicts of Interest: The authors declare no conflict of interest.

\section{References}

1. Paulson, H. Repeat expansion diseases. In Handbook of Clinical Neurology; Elsevier: Amsterdam, The Netherlands, 2018; Volume 147, pp. 105-123, ISBN 978-0-444-63233-3. 
2. Brook, J.D.; McCurrach, M.E.; Harley, H.G.; Buckler, A.J.; Church, D.; Aburatani, H.; Hunter, K.; Stanton, V.P.; Thirion, J.-P.; Hudson, T.; et al. Molecular Basis of Myotonic Dystrophy: Expansion of a Trinucleotide (CTG) Repeat at the 3' End of a Transcript Encoding a Protein Kinase Family Member. Cell 1992, 68, 799-808. [CrossRef]

3. Tomé, S.; Gourdon, G. DM1 Phenotype Variability and Triplet Repeat Instability: Challenges in the Development of New Therapies. Int. J. Mol. Sci. 2020, 21, 457. [CrossRef] [PubMed]

4. De Antonio, M.; Dogan, C.; Hamroun, D.; Mati, M.; Zerrouki, S.; Eymard, B.; Katsahian, S.; Bassez, G. Unravelling the Myotonic Dystrophy Type 1 Clinical Spectrum: A Systematic Registry-Based Study with Implications for Disease Classification. Rev. Neurol. 2016, 172, 572-580. [CrossRef]

5. Dogan, C.; De Antonio, M.; Hamroun, D.; Varet, H.; Fabbro, M.; Rougier, F.; Amarof, K.; Arne Bes, M.-C.; Bedat-Millet, A.-L.; Behin, A.; et al. Gender as a Modifying Factor Influencing Myotonic Dystrophy Type 1 Phenotype Severity and Mortality: A Nationwide Multiple Databases Cross-Sectional Observational Study. Plos ONE 2016, 11, e0148264. [CrossRef] [PubMed]

6. Morales, F.; Couto, J.M.; Higham, C.F.; Hogg, G.; Cuenca, P.; Braida, C.; Wilson, R.H.; Adam, B.; del Valle, G.; Brian, R.; et al. Somatic Instability of the Expanded CTG Triplet Repeat in Myotonic Dystrophy Type 1 Is a Heritable Quantitative Trait and Modifier of Disease Severity. Hum. Mol. Genet. 2012, 21, 3558-3567. [CrossRef] [PubMed]

7. Lee, J.-M.; Correia, K.; Loupe, J.; Kim, K.-H.; Barker, D.; Hong, E.P.; Chao, M.J.; Long, J.D.; Lucente, D.; Vonsattel, J.P.G.; et al. CAG Repeat Not Polyglutamine Length Determines Timing of Huntington's Disease Onset. Cell 2019, 178, 887-900.e14. [CrossRef] [PubMed]

8. Morales, F.; Vásquez, M.; Corrales, E.; Vindas-Smith, R.; Santamaría-Ulloa, C.; Zhang, B.; Sirito, M.; Estecio, M.R.; Krahe, R.; Monckton, D.G. Longitudinal Increases in Somatic Mosaicism of the Expanded CTG Repeat in Myotonic Dystrophy Type 1 Are Associated with Variation in Age-at-Onset. Hum. Mol. Genet. 2020, 29, 2496-2507. [CrossRef]

9. Overend, G.; Légaré, C.; Mathieu, J.; Bouchard, L.; Gagnon, C.; Monckton, D.G. Allele Length of the DMPK CTG Repeat Is a Predictor of Progressive Myotonic Dystrophy Type 1 Phenotypes. Hum. Mol. Genet. 2019, 28, 2245-2254. [CrossRef] [PubMed]

10. Cumming, S.A.; Jimenez-Moreno, C.; Okkersen, K.; Wenninger, S.; Daidj, F.; Hogarth, F.; Littleford, R.; Gorman, G.; Bassez, G.; Schoser, B.; et al. Genetic Determinants of Disease Severity in the Myotonic Dystrophy Type 1 OPTIMISTIC Cohort. Neurology 2019, 93, e995-e1009. [CrossRef]

11. Morales, F.; Vásquez, M.; Santamaría, C.; Cuenca, P.; Corrales, E.; Monckton, D.G. A Polymorphism in the MSH3 Mismatch Repair Gene Is Associated with the Levels of Somatic Instability of the Expanded CTG Repeat in the Blood DNA of Myotonic Dystrophy Type 1 Patients. DNA Repair 2016, 40, 57-66. [CrossRef]

12. Flower, M.; Lomeikaite, V.; Ciosi, M.; Cumming, S.; Morales, F.; Lo, K.; Hensman Moss, D.; Jones, L.; Holmans, P.; Monckton, D.G.; et al. MSH3 Modifies Somatic Instability and Disease Severity in Huntington's and Myotonic Dystrophy Type 1. Brain 2019, 142, 1876-1886. [CrossRef] [PubMed]

13. Latham, G.J.; Coppinger, J.; Hadd, A.G.; Nolin, S.L. The Role of AGG Interruptions in Fragile X Repeat Expansions: A Twenty-Year Perspective. Front. Genet. 2014, 5, 244. [CrossRef] [PubMed]

14. Matsuyama, Z.; Izumi, Y.; Kameyama, M.; Kawakami, H.; Nakamura, S. The EVect of CAT Trinucleotide Interruptions on the Age at Onset of Spinocerebellar Ataxia Type 1. J. Med. Genet. 1999, 36, 546-548. [PubMed]

15. Kraus-Perrotta, C.; Lagalwar, S. Expansion, Mosaicism and Interruption: Mechanisms of the CAG Repeat Mutation in Spinocerebellar Ataxia Type 1. Cerebellum Ataxias 2016, 3, 20. [CrossRef] [PubMed]

16. Tomé, S.; Dandelot, E.; Dogan, C.; Bertrand, A.; Geneviève, D.; Péréon, Y.; Simon, M.; Bonnefont, J.-P.; Bassez, G.; Gourdon, G. Unusual Association of a Unique CAG Interruption in $5^{\prime}$ of DM1 CTG Repeats with Intergenerational Contractions and Low Somatic Mosaicism. Hum. Mutat. 2018, 39, 970-982. [CrossRef]

17. Braida, C.; Stefanatos, R.K.A.; Adam, B.; Mahajan, N.; Smeets, H.J.M.; Niel, F.; Goizet, C.; Arveiler, B.; Koenig, M.; LagierTourenne, C.; et al. Variant CCG and GGC Repeats within the CTG Expansion Dramatically Modify Mutational Dynamics and Likely Contribute toward Unusual Symptoms in Some Myotonic Dystrophy Type 1 Patients. Hum. Mol. Genet. 2010, 19, 1399-1412. [CrossRef]

18. The Scottish Myotonic Dystrophy Consortium; Cumming, S.A.; Hamilton, M.J.; Robb, Y.; Gregory, H.; McWilliam, C.; Cooper, A.; Adam, B.; McGhie, J.; Hamilton, G.; et al. De Novo Repeat Interruptions Are Associated with Reduced Somatic Instability and Mild or Absent Clinical Features in Myotonic Dystrophy Type 1. Eur. J. Hum. Genet. 2018, 26, 1635-1647. [CrossRef] [PubMed]

19. Santoro, M.; Masciullo, M.; Silvestri, G.; Novelli, G.; Botta, A. Myotonic Dystrophy Type 1: Role of CCG, CTC and CGG Interruptions within DMPK Alleles in the Pathogenesis and Molecular Diagnosis: Variant Interruptions in Pathogenesis and Molecular Diagnosis of DM1. Clin. Genet. 2017, 92, 355-364. [CrossRef] [PubMed]

20. Santoro, M.; Masciullo, M.; Pietrobono, R.; Conte, G.; Modoni, A.; Bianchi, M.L.E.; Rizzo, V.; Pomponi, M.G.; Tasca, G.; Neri, G.; et al. Molecular, Clinical, and Muscle Studies in Myotonic Dystrophy Type 1 (DM1) Associated with Novel Variant CCG Expansions. J. Neurol. 2013, 260, 1245-1257. [CrossRef] [PubMed]

21. Ballester-Lopez, A.; Koehorst, E.; Almendrote, M.; Martínez-Piñeiro, A.; Lucente, G.; Linares-Pardo, I.; Núñez-Manchón, J.; Guanyabens, N.; Cano, A.; Lucia, A.; et al. A DM1 Family with Interruptions Associated with Atypical Symptoms and Late Onset but Not with a Milder Phenotype. Hum. Mutat. 2020, 41, 420-431. [CrossRef] [PubMed]

22. Pešović, J.; Perić, S.; Brkušanin, M.; Brajušković, G.; Rakočević-Stojanović, V.; Savić-Pavićević, D. Repeat Interruptions Modify Age at Onset in Myotonic Dystrophy Type 1 by Stabilizing DMPK Expansions in Somatic Cells. Front. Genet. 2018, 9, 601. [CrossRef] [PubMed] 
23. Miller, J.N.; van der Plas, E.; Hamilton, M.; Koscik, T.R.; Gutmann, L.; Cumming, S.A.; Monckton, D.G.; Nopoulos, P.C. Variant Repeats within the DMPK CTG Expansion Protect Function in Myotonic Dystrophy Type 1. Neurol. Genet. 2020, 6, e504. [CrossRef] [PubMed]

24. Radvansky, J.; Ficek, A.; Minarik, G.; Palffy, R.; Kadasi, L. Effect of Unexpected Sequence Interruptions to Conventional PCR and Repeat Primed PCR in Myotonic Dystrophy Type 1 Testing. Diagn. Mol. Pathol. 2011, 20, 48-51. [CrossRef] [PubMed]

25. De Siena, C.; Cardani, R.; Brigonzi, E.; Bosè, F.; Fossati, B.; Meola, G.; Costa, E.; Valaperta, R. Incidence of Amplification Failure in DMPK Allele Due to Allelic Dropout Event in a Diagnostic Laboratory. Clin. Chim. Acta 2018, 484, 111-116. [CrossRef]

26. Botta, A.; Rossi, G.; Marcaurelio, M.; Fontana, L.; D’Apice, M.R.; Brancati, F.; Massa, R.; G Monckton, D.; Sangiuolo, F.; Novelli, G. Identification and Characterization of 5' CCG Interruptions in Complex DMPK Expanded Alleles. Eur. J. Hum. Genet. 2017, 25, 257-261. [CrossRef] [PubMed]

27. Santoro, M.; Fontana, L.; Masciullo, M.; Bianchi, M.L.E.; Rossi, S.; Leoncini, E.; Novelli, G.; Botta, A.; Silvestri, G. Expansion Size and Presence of CCG/CTC/CGG Sequence Interruptions in the Expanded CTG Array Are Independently Associated to Hypermethylation at the DMPK Locus in Myotonic Dystrophy Type 1 (DM1). Biochim. Biophys. Acta (BBA) Mol. Basis Dis. 2015, 1852, 2645-2652. [CrossRef] [PubMed]

28. Addis, M.; Serrenti, M.; Meloni, C.; Cau, M.; Melis, M.A. Triplet-Primed PCR Is More Sensitive than Southern Blotting-Long PCR for the Diagnosis of Myotonic Dystrophy Type1. Genet. Test. Mol. Biomark. 2012, 16, 1428-1431. [CrossRef] [PubMed]

29. Fontana, L.; Santoro, M.; D'Apice, M.R.; Gori, G.; Morrone, A.; Novelli, G.; Botta, A. Identification, Molecular Characterization and Segregation Analysis of a Variant DMPK Pre-Mutation Allele in a Three-Generation Italian Family. Acta. Myol. 2020, 39, 13-18. [CrossRef] [PubMed]

30. Lian, M.; Law, H.-Y.; Lee, C.G.; Chong, S.S. Defining the Performance Parameters of a Rapid Screening Tool for Myotonic Dystrophy Type 1 Based on Triplet-Primed PCR and Melt Curve Analysis. Expert Rev. Mol. Diagn. 2016, 16, 1221-1232. [CrossRef] [PubMed]

31. P. Leeflang, E.; Arnhelm, N. A Novel Repeat Structure at the Myotonic Dystrophy Locus in a 37 Repeat Allele with Unexpectedly High Stability. Hum. Mol. Genet. 1995, 4, 135-136. [CrossRef]

32. Musova, Z.; Mazanec, R.; Krepelova, A.; Ehler, E.; Vales, J.; Jaklova, R.; Prochazka, T.; Koukal, P.; Marikova, T.; Kraus, J.; et al. Highly Unstable Sequence Interruptions of the CTG Repeat in the Myotonic Dystrophy Gene. Am. J. Med. Genet. 2009, 149A, 1365-1374. [CrossRef]

33. Tomé, S.; Gourdon, G. Fast Assays to Detect Interruptions in CTG.CAG Repeat Expansions. In Trinucleotide Repeats; Richard, G.-F., Ed.; Methods in Molecular Biology; Springer: New York, NY, USA, 2020; Volume 2056, pp. 11-23. ISBN 978-1-4939-9783-1.

34. Warner, J.P.; Barron, L.H.; Goudie, D.; Kelly, K.; Dow, D.; Fitzpatrick, D.R.; Brock, D.J. A General Method for the Detection of Large CAG Repeat Expansions by Fluorescent PCR. J. Med. Genet. 1996, 33, 1022-1026. [CrossRef] [PubMed]

35. Mantere, T.; Kersten, S.; Hoischen, A. Long-Read Sequencing Emerging in Medical Genetics. Front. Genet. 2019, 10, 426. [CrossRef] [PubMed]

36. Loomis, E.W.; Eid, J.S.; Peluso, P.; Yin, J.; Hickey, L.; Rank, D.; McCalmon, S.; Hagerman, R.J.; Tassone, F.; Hagerman, P.J. Sequencing the Unsequenceable: Expanded CGG-Repeat Alleles of the Fragile X Gene. Genome Res. 2013, 23, 121-128. [CrossRef] [PubMed]

37. Höijer, I.; Tsai, Y.-C.; Clark, T.A.; Kotturi, P.; Dahl, N.; Stattin, E.-L.; Bondeson, M.-L.; Feuk, L.; Gyllensten, U.; Ameur, A. Detailed Analysis of HTT Repeat Elements in Human Blood Using Targeted Amplification-Free Long-Read Sequencing. Hum. Mutat. 2018, 39, 1262-1272. [CrossRef] [PubMed]

38. Mitsuhashi, S.; Matsumoto, N. Long-Read Sequencing for Rare Human Genetic Diseases. J. Hum. Genet. 2020, 65, 11-19. [CrossRef] [PubMed]

39. E. Neville, C.; S. Mahadeva, M.; M. Barcelo, J.; Korneluk, R. High Resolution Genetic Analysis Suggests One Ancestral Predisposing Haplotype for the Origin of the Myotonic Dystrophy Mutation. Hum. Mol. Genet. 1994, 3, 45-51. [CrossRef] [PubMed]

40. Imbert, G.; Kretz, C.; Johnson, K.; Mandel, J.L. Origin of the Expansion Mutation in Myotonic Dystrophy. Nat. Genet. 1993, 4, 72-76. [CrossRef]

41. Murillo-Melo, N.M.; Márquez-Quiróz, L.C.; Gómez, R.; Orozco, L.; Mendoza-Caamal, E.; Tapia-Guerrero, Y.S.; CamachoMejorado, R.; Cortés, H.; López-Reyes, A.; Santana, C.; et al. Origin of the Myotonic Dystrophy Type 1 Mutation in Mexican Population and Influence of Amerindian Ancestry on CTG Repeat Allelic Distribution. Neuromuscul. Disord. 2017, 27, 1106-1114. [CrossRef]

42. Franck, S.; Barbé, L.; Ardui, S.; De Vlaeminck, Y.; Allemeersch, J.; Dziedzicka, D.; Spits, C.; Vanroye, F.; Hilven, P.; Duqué, G.; et al. MSH2 Knock-down Shows CTG Repeat Stability and Concomitant Upstream Demethylation at the DMPK Locus in Myotonic Dystrophy Type 1 Human Embryonic Stem Cells. Hum. Mol. Genet. 2020, ddaa250. [CrossRef]

43. Hiatt, S.M.; Lawlor, J.M.J.; Handley, L.H.; Ramaker, R.C.; Rogers, B.B.; Partridge, E.C.; Boston, L.B.; Williams, M.; Plott, C.B.; Jenkins, J.; et al. Long-Read. Genome Sequencing for the Diagnosis of Neurodevelopmental Disorders. Hum. Genet. Genom. Adv. 2021, 2. [CrossRef]

44. Lavedan, C.; Hofmann-Radvanyi, H.; Duros, C.; Savoy, D.; Dehaupas, I.; Luce, P.S.; Junien, C. Myotonic Dystrophy: Size- and Sex-Dependent Dynamics of CTG Meiotic Instability, and Somatic Mosaicism. Am. J. Hum. Genet. 1993, 52, 875-883. [PubMed] 
45. Morales, F.; Vásquez, M.; Cuenca, P.; Campos, D.; Santamaría, C.; del Valle, G.; Brian, R.; Sittenfeld, M.; Monckton, D.G. Parental Age Effects, but No Evidence for an Intrauterine Effect in the Transmission of Myotonic Dystrophy Type 1. Eur. J. Hum. Genet. 2015, 23, 646-653. [CrossRef]

46. Joosten, I.B.T.; Hellebrekers, D.M.E.I.; de Greef, B.T.A.; Smeets, H.J.M.; de Die-Smulders, C.E.M.; Faber, C.G.; Gerrits, M.M Parental Repeat Length Instability in Myotonic Dystrophy Type 1 Pre- and Protomutations. Eur. J. Hum. Genet. 2020, $28,956-962$. [CrossRef] [PubMed]

47. Martorell, L.; Johnson, K.; Boucher, C.A.; Baiget, M. Somatic Instability of the Myotonic Dystrophy (CTG)n Repeat during Human Fetal Development. Hum. Mol. Genet. 1997, 6, 877-880. [CrossRef] [PubMed]

48. Wöhrle, D.; Kennerknecht, I.; Wolf, M.; Enders, H.; Schwemmle, S.; Steinbach, P. Heterogeneity of DM Kinase Repeat Expansion in Different Fetal Tissues and Further Expansion during Cell Proliferation in Vitro: Evidence for a Casual Involvement of Methyl-Directed DNA Mismatch Repair in Triplet Repeat Stability. Hum. Mol. Genet. 1995, 4, 1147-1153. [CrossRef] [PubMed]

49. Hafford-Tear, N.J.; Tsai, Y.-C.; Sadan, A.N.; Sanchez-Pintado, B.; Zarouchlioti, C.; Maher, G.J.; Liskova, P.; Tuft, S.J.; Hardcastle, A.J.; Clark, T.A.; et al. CRISPR/Cas9-Targeted Enrichment and Long-Read Sequencing of the Fuchs Endothelial Corneal DystrophyAssociated TCF4 Triplet Repeat. Genet. Med. 2019, 21, 2092-2102. [CrossRef] [PubMed]

50. The Filnemus Myotonic Dystrophy Study Group; De Antonio, M.; Dogan, C.; Daidj, F.; Eymard, B.; Puymirat, J.; Mathieu, J.; Gagnon, C.; Katsahian, S.; Hamroun, D.; et al. The DM-Scope Registry: A Rare Disease Innovative Framework Bridging the Gap between Research and Medical Care. Orphanet J. Rare Dis. 2019, 14, 122. [CrossRef]

51. Procedure E Checklist_-Preparing SMRTbell Libraries Using PacBio Barcoded Universal Primers for Multiplexing Amplicons; PacBio: Menlo Park, CA, USA, 2020. 